\title{
Currency Risk Factors in a Recursive Multi-Country Economy
}

\author{
R. Colacito \\ M. M. Croce \\ F. Gavazzoni \\ R. Ready*
}

\begin{abstract}
Focusing on the ten most-traded currencies, we provide empirical evidence about a significant heterogenous exposure to global growth news shocks. We incorporate this empirical fact in a frictionless risk-sharing model with recursive preferences, multiple countries, and multiple consumption goods whose supply features both global and local short- and long-run shocks. Since news shocks are priced, heterogenous exposure to global long-lasting growth shocks results in a relevant reallocation of international resources and currency adjustments. Our unified framework replicates the properties of the HML-FX and HML-NFA carry trade strategies studied by Lustig et al. (2011) and Della Corte et al. (2013).
\end{abstract}

JEL classification: C62; F31; G12.

This draft: November 23, 2015.

${ }^{*}$ Colacito and Croce are affiliated with the Kenan-Flagler Business School at the University of North Carolina-Chapel Hill. Gavazzoni is affiliated with INSEAD. Ready is affiliated with the Simon School at the University of Rochester. We thank Bernard Dumas, Xavier Gabaix, and Tarek Hassan for early feedback. We also thank our discussants Philippe Bacchetta, Emmanuel Farhi, Pierre-Olivier Gourinchas, Christian Heyerdahl-Larsen and Matteo Maggiori, along with seminar participants at INSEAD, the NBER SI (IAP group), the meetings of the Econometric Society, the annual meeting of the European Finance Association, the Macro-Finance Society Conference, BI Norwegian Business School, and annual meetings of the American Economic Association, for useful comments and insights. All errors remain our own. 


\section{Introduction}

A growing empirical literature in international finance examines the structure of risk in the cross section of currency returns (see, among others, Lustig and Verdelhan 2007, Lustig et al. 2014, and Della Corte et al. 2013). These studies sort currencies on various criteria and highlight the empirical relevance of several economic and financial factors. In this paper we provide novel empirical evidence in support of a structural dynamic equilibrium model that can account for these factor structures in the context of a news shocks-based asset-pricing model. According to our findings, heterogenous exposure to global growth news shocks is a key driver of currency riskiness, interest rates, and international lending positions in the cross section of countries.

Specifically, we analyze an economy populated by multiple countries engaged in a frictionless recursive risk-sharing scheme, in the spirit of Colacito and Croce (2013). This model features long-run growth news shocks, which are directly priced by Epstein and Zin (1989) recursive preferences. This setting is of particular interest given its documented ability to account for several empirical regularities of the joint dynamics of international asset prices and quantities in a two-country setting (see Colacito 2008, Colacito and Croce 2011, and Bansal and Shaliastovich 2013). We expand and generalize this setting in at least two relevant directions.

In a first step, we show that the ability of the Colacito and Croce (2013) model to replicate the failure of the uncovered interest parity is not sufficient to produce a risk

premium in the cross section of interest-rate sorted currencies. That is, the mean of the Lustig et al. (2011) HML-FX factor is close to zero in a model in which countries have the same endowment exposure to global news shocks.

In a second step, we introduce heterogenous exposure to growth news shocks in the 
cross section of countries, in a way that is consistent with our novel empirical evidence on the ten countries with the most-traded currencies (henceforth G-10 countries). Specifically, we model a very persistent stochastic heterogeneity in the exposure of country-level endowments to long-run global growth news. The long-run wealth distribution in this economy is well defined, since we are still adopting a symmetric calibration (see Colacito and Croce 2012). In finite samples, however, our countries feature substantial heterogeneity, consistent with the empirical investigation by Lustig et al. (2011) and Hassan and Mano (2014). These heterogenous loadings are a reduced-form way of capturing a mix of fundamental differences across countries, such as size (Hassan 2013), commodity intensity (Ready et al. 2012), monetary policy rules (Backus et al. 2010), and financial development (Maggiori 2011).

Under our benchmark calibration, we are able to produce an average HML annual spread of about 3\%, as large as the unconditional HML-FX in the data. This currency risk premium originates from a positive correlation between the returns to carrytrade and global long-run consumption news. When a negative long-run shock hits, the carry trade yields a negative return, due to the appreciation of the funding currencies (i.e., the high-exposure countries). In good times, the carry trade earns a positive return due to the appreciation of the investment currencies (i.e., low-exposure countries).

We also show that this setting can replicate the empirical distribution of currencyportfolio betas on the HML factor. In addition, we document that, in our model, sorting countries on interest rates is equivalent to sorting on net foreign asset (henceforth NFA) positions and exposure to long-run global growth news. This suggests that the factors proposed by Della Corte et al. (2013) and Lustig et al. (2011) may be the risk-sharing outcome of a single fundamental source of heterogeneity, i.e., different exposure to global long-run growth news. 
To discipline our calibration, we use macroeconomic data from the ten most traded currencies in the world. In our cross section of countries, the price-dividend ratio is a statistically significant predictor of future growth rates of output. For this reason, in each country we use the projection of the GDP growth rate onto lagged values of the price-dividend ratio as our measure of long-run growth. We denote the innovations to this estimated component as long-run growth news shocks, and show that they have a sizeable impact on countries' future growth prospects. We use the residual of our predictive regressions as a measure of short-run growth shocks. In a second step, we regress each country's long-run risk on the cross-sectional average long-run risk in our cross section of countries and view the estimated coefficients as a measure of each country's exposure to global long-run risk. We find a substantial degree of heterogeneity in the estimated exposures.

In particular, countries like Australia and New Zealand, which are commonly featured in the long leg of carry-trade strategies, have very low exposures to global longrun risk. In contrast, countries like Switzerland, which represents a typical funding currency in the carry trade, feature a substantially higher degree of exposure to global long-run risk. Interestingly, we cannot identify any heterogeneity in terms of the exposure to global short-run risk, implying that abstracting away from growth news shocks would prevent us from identifying a key driver of the international heterogeneity.

Our theoretical explanation of the cross section of currency risk premia produces a rich set of novel testable predictions. We document that sorting the average risk-free rates, the volatility of exchange rates, and the first two moments of net foreign asset positions with respect to the exposure to global long-run risks produces the same patterns in the model and in the data.

In addition, we explore the time-series relation between the cross section of exposures 
to global long-run risks and international capital flows. According to our model, when a negative global shock materializes, the countries that are less exposed to global shocks should provide insurance to the countries with a large degree of exposure to global shocks. That is, countries with lower exposure to global long-run news should experience a deterioration of their net foreign asset positions, whereas highly exposed countries should retain a larger balance of net foreign assets.

We provide empirical support for this prediction by showing that countries like Australia and New Zealand experience a large drop (increase) in their net foreign asset positions, in times of negative (positive) long-run global growth prospects. Countries on the other end of the spectrum, such as Switzerland, experience a large inflow (outflow) of assets from abroad, whenever global long-run growth prospects are weak (strong). Furthermore, the currencies of large-exposure countries have the tendency to appreciate in bad times relative to the currencies of low-exposure countries, a finding which is also consistent with our model.

Our analysis helps to shed light on the connection between currency risk and countrylevel characteristics related to international trade. On the one hand, we provide equilibrium foundations to the reduced-form analysis of Lustig et al. (2011), Zviadadze (2013) and Farhi et al. (2015). On the other hand, we reconcile currency risk factors with macroeconomic fundamentals by analyzing directly the role of international asset positions (Gourinchas and Rey 2007, Caballero et al. 2008, and Gourio et al. 2014). Furthermore, our benchmark model with heterogenous exposure to growth news is consistent with Verdelhan (2015), as it enables global long-run shocks to contribute to bilateral exchange rate variance.

Our study is also related to the growing body of literature that has investigated the macroeconomic foundations of international financial markets' fluctuations (see, inter alia, Farhi and Gabaix 2008, Hassan 2013, Stathopoulos 2012, Heyerdahl-Larsen 
2015, and Verdelhan 2010). Our empirical evidence on the 2007 Great Recession is related to the work on rare disasters (Barro 2006, Gabaix 2012, and Gourio 2012) and its applications to international finance (see, for example, Gourio et al. 2014). Although our attention is focused on a frictionless risk-sharing setting, we regard the introduction of frictions in our model as an important direction for future research in this area (see, for example, Gabaix and Maggiori 2015, Froot and Stein 1991, and Farhi and Werning 2014).

In the next section we report our empirical evidence concerning the heterogenous exposure to global long-run risk in G-10 countries. In section 3, we provide asset pricing intuitions in a simple economy with recursive preferences. In section 4 we present our risk-sharing model and our equilibrium conditions. Section 5 presents our main results, and section 6 concludes.

\section{Empirical Analysis}

Data sources. For our empirical work we focus on the set of G-10 currency countries: Australia, Canada, Germany, Japan, Norway, New Zealand, Sweden, Switzerland, the United Kingdom, and the United States. These countries have highly developed economies with high levels of global financial integration and highly liquid currencies, yet they still provide a rich set of cross-sectional empirical differences. We therefore view them as an appropriate setting in which to test the predictions of our model, which features heterogenous exposure to global risk in the presence of complete financial markets.

Data on consumption and net exports are from the Organisation for Economic Cooperation and Development (OECD). We use the volume index of the private final consumption expenditure series as our consumption series, and the difference be- 
tween the volume indices of exports of goods and services and imports of goods and services as our net export series. In what follows, the variable $\Delta G D P_{t}$ proxies for total endowment growth and is computed as the growth in consumption plus net exports for the entire cross section of countries that we use in our empirical investigation. We exclude investment and government expenditure from our empirical measure to be consistent with our endowment economy in which we abstract away from both physical investment and demand for public goods. Data on net foreign assets come from the updated and extended version of the data set constructed by Lane and Milesi-Ferretti (2007). ${ }^{1}$

Data on interest rates and inflation are also from the OECD. Real interest rates are constructed using 3-month interbank rates from the OECD, adjusting for realized inflation using the annual changes in CPI. Norwegian interest rates prior to 1979 are obtained from Stats Norway. Swedish 3-month rates prior to 1982 are extrapolated from overnight rates reported by the OECD and long-term rates reported by Statistics Sweden. International price-dividend ratios are calculated using Kenneth French's cum- and ex-dividend country value-weighted dollar index returns. ${ }^{2}$

All exchange rate data are collected relative to the US dollar. Exchange rate data for Australia, Canada, Japan, New Zealand, Norway, Sweden, Switzerland, and the UK are obtained from the Board of Governors of the Federal Reserve. Exchange rate data for Germany are obtained from the OECD. The sample period is 1971-2014. Real exchange rates are obtained by dividing by the relative CPI index of the corresponding country.

Estimation procedure. We follow Colacito and Croce (2013) and Bansal et al. (2010) in identifying short- and long-run innovations to GDP growth rates by means of pre-

\footnotetext{
${ }^{1}$ Data graciously provided on Philip Lane's website: http://www.philiplane.org/EWN.html.

${ }^{2} \mathrm{http} / / / \mathrm{mba} . t u c k . d a r t m o u t h . e d u /$ pages/faculty/ken.french/data_library.html
} 
dictive regressions. Specifically, we interpret the projection of $\Delta G D P_{t}$ in each country onto lagged values of that country's price-dividend ratio as our measure of long-run risk. A balanced panel of price-dividend ratios starts in 1987, so we use this sample to estimate global risk exposure. The estimation of all the parameters of interest is obtained from the following specification:

$$
\begin{aligned}
\Delta G D P_{t}^{i} & =\phi \cdot p d_{t-1}^{i}+\sigma \cdot \underbrace{\varepsilon_{t}^{i}}_{\text {Short-Run Shock }} \\
z_{t}^{i} & =\rho_{z} \cdot z_{t-1}^{i}+\varphi_{e} \cdot \sigma \cdot \underbrace{\varepsilon_{z, t}^{i}}_{\text {Long-Run Shock }},
\end{aligned}
$$

$\forall i \in\{\mathrm{G}-10$ countries $\}$ and where $z_{t}^{i}=\phi \cdot p d_{t}^{i}$ is our measure of the long-run risk in country $i$. We omit the intercepts because all variables are demeaned. Furthermore, we pool the estimation of the parameters $\left(\phi, \sigma, \rho_{z}, \varphi_{e}\right)$ for parsimony. The system in (1) is estimated using GMM, and standard errors take into account both serial and crosssectional correlation.

We report the results of our estimation in Panel A of Table 1. Several interesting findings emerge. First, all estimated parameters are statistically significant, suggesting the relevance of lagged price-dividend ratios as source of predictability for future growth rates of macroeconomic variables. Second, the projection of GDP growth rate on lagged price-dividend ratio is highly persistent, with an annual autocorrelation on the order of 0.77 . This implies that shocks to the price-dividend ratio are likely to have long-lasting effects on the future dynamics of the growth rate of GDP. Third, the shocks to the predictive component of GDP growth rate are small compared to the magnitude of the short-run shocks, i.e., the parameter $\varphi_{e}$ is on the order of 0.06. All of these features of the data discipline the calibration of the model that we present in the next sections. 


\section{TABLE 1: Dynamics of Endowments and Predictive Components}

\begin{tabular}{lcccc} 
Panel A: Estimation of Predictive Components & & \\
\hline \multicolumn{7}{l}{$\phi$} & $\rho_{x}$ & $\sigma$ & $\varphi_{e}$ \\
\hline Parameters & $\phi$ & $0.773^{* * *}$ & $0.020^{* * *}$ & $0.058^{* * *}$ \\
(S.E.) & $0.005^{* * *}$ & $(0.006)$ & $(0.000)$ & $(0.001)$ \\
\hline
\end{tabular}

Panel B: Exposure to Global Endowment Risk

\begin{tabular}{|c|c|c|c|c|c|c|c|c|c|c|}
\hline & NZ & AUS & UK & GER & $\mathbf{C A N}$ & NOR & JPN & SUI & US & SWE \\
\hline $\begin{array}{l}\beta_{\Delta y}^{i} \\
\text { (S. } \mathrm{E} \text { ) }\end{array}$ & $\begin{array}{l}-0.28 \\
(0.299)\end{array}$ & $\begin{array}{l}-0.18 \\
(0.234)\end{array}$ & $\begin{array}{c}0.05 \\
(0.164)\end{array}$ & $\begin{array}{l}-0.12 \\
(0.218)\end{array}$ & $\begin{array}{c}0.14^{*} \\
(0.085)\end{array}$ & $\begin{array}{c}0.61^{* *} \\
(0.269)\end{array}$ & $\begin{array}{c}0.15 \\
(0.269)\end{array}$ & $\begin{array}{l}-0.11 \\
(0.177)\end{array}$ & $\begin{array}{l}-0.11 \\
(0.104)\end{array}$ & $\begin{array}{l}-0.16 \\
(0.199)\end{array}$ \\
\hline
\end{tabular}

Panel C: Exposure to Global Long-Run Risk

\begin{tabular}{lcccccccccc}
\hline & NZ & AUS & UK & GER & CAN & NOR & JPN & SUI & US & SWE \\
\hline$\beta^{i}$ & $-0.51^{* * *}$ & $-0.44^{* * *}$ & -0.08 & -0.02 & 0.00 & 0.08 & 0.12 & $0.26^{* *}$ & $0.27^{*}$ & $0.33^{* *}$ \\
(S.E.) & $(0.154)$ & $(0.064)$ & $(0.098)$ & $(0.094)$ & $(0.131)$ & $(0.173)$ & $(0.165)$ & $(0.130)$ & $(0.166)$ & $(0.148)$ \\
Chow & {$[0.109]$} & {$[0.245]$} & {$[0.299]$} & {$[0.841]$} & {$[0.729]$} & {$[0.506]$} & {$[0.802]$} & {$[0.667]$} & {$[0.596]$} & {$[0.385]$} \\
\hline
\end{tabular}

Notes - Panel A reports the estimation of the parameters of the endowment process reported in equation (1). The numbers in parentheses are heteroskedasticity-adjusted standard errors. The parameters are estimated using the longest available sample for each country, as described in section 2. Panel B reports the estimation of the exposure of each country's GDP growth rate to the global GDP growth rate (see equation (2)). The sample is 1970-2013. The numbers in parentheses are heteroskedasticity-adjusted standard errors. Panel $\mathrm{C}$ reports the estimation of the exposure of each country's predictive component of GDP to the global predictive component (see equation (3)). The sample is 1987-2013. The numbers in parentheses are heteroskedasticity-adjusted standard errors. The numbers in square brackets are the $p$ values associated to the null hypthesis that the estimated exposure in the first half of the sample (1987-2000) is different from the estimated exposure in the second half of the sample (2001-2013). In all panels, one, two, and three stars denote statistical significance at the 10\%, $5 \%$, and $1 \%$ levels, respectively.

Exposure to global risk. In Panel B of Table 1 we document the exposure of each country's endowment to a measure of global endowment risk. Specifically, we regress each country's GDP growth rate, $\Delta G D P_{t}^{i}$, on the average of all countries' GDP growth rates:

$$
\Delta G D P_{t}^{i}=\left(1+\beta_{\Delta y}^{i}\right) \cdot\left(\frac{1}{n} \sum_{i=1}^{n} \Delta G D P_{t}^{i}\right)+\xi_{t}^{i}, \quad \forall i \in\{\mathrm{G} 10 \text { countries }\}
$$

With the sole exception of Norway and Canada, we cannot reject the null hypothesis that all the estimated coefficients in Panel B of Table 1 are equal to zero. Equivalently, looking at global endowment growth does not generate any significant form of heterogeneity in the cross section. 
This conclusion is completely reversed when we focus on the exposure to global longrun news. Specifically, we measure the loading of each country's long-run risk on a global measure of long-run risk by regressing each $z_{t}^{i}$ estimated in (1) on the average of all $z_{t}^{i}$ s:

$$
z_{t}^{i}=\left(1+\beta^{i}\right) \cdot\left(\frac{1}{n} \sum_{i=1}^{n} z_{t}^{i}\right)+\zeta_{t}^{i}, \quad \forall i \in\{\mathrm{G}-10 \text { countries }\}
$$

We estimate these coefficients using the longest common sample across all countries, 1987-2013, and report our results in Panel C of Table 1. We note that there is a sizeable degree of dispersion in the estimated $\beta^{i}$ s, which range from -0.51 for New Zealand to 0.33 for Sweden. Furthermore, the estimated coefficients are statistically different from zero for the most extreme countries. In Panel B, we also report the $p$-values associated with a Chow test for the null hypothesis that the $\beta^{i}$ 's are statistically different in the first and second halves of our sample. We always reject the null at conventional confidence levels.

According to our analysis, the US is a country with relatively high exposure to global long-run risk. This finding does not contradict the Lustig and Verdelhan (2007)'s view of the US being an average country in the cross-sectional distribution of real interest rates. Specifically, the US had a relatively high real rate in the first part of the post-Bretton-Woods era (see panel (a) of Figure D2 in Appendix), but not in the more recent sample period that we consider.

Equivalently, an econometrician focusing on the entire sample would conclude that the US has been on average a median interest rate country, whereas someone looking at the post-1987 sample would conclude that the US is a below median country.

Similar considerations apply to Japan. Table 1 indicates that Japan is not the country with the highest exposure to global long-run risk, a finding which may seem at odds 
with the idea that the Japanese Yen should a funding currency in the carry trade. We note that the real interest rate in Japan has been extremely low until the early 2000 s, but it has since sharply increased in the cross-section of interest rates observed among our G-10 countries (see panel (b) of Figure D2).

Our empirical findings motivate the theoretical analysis presented in the next sections. We show that modeling the presence of persistent and stable heterogeneity in the exposure to global long-run risk across countries reconciles several features of the cross section of real interest rates, equity premia, and currency risks.

\section{Asset pricing intuitions in a simple economy with recursive preferences}

In this section we introduce a simple partial equilibrium model with recursive preferences and news shocks for which there exist analytical solutions. In this context, we prove that: i) the profitability of the carry trade and the violation of the uncovered interest rate parity relationship are distinct phenomena that require different explanations; ii) the heterogenous exposure to the global long-run risk is necessary to account for the carry trade risk-premium, but not for the forward premium anomaly; iii) time-varying volatility is needed to obtain departures from UIP, but is not necessary to generate a positive carry trade premium, and iv) recursive preferences are necessary to obtain plausible quantitative results along all these dimensions.

This partial equilibrium model sets the stage for our general equilibrium analysis subject to two limitations. First, in this section we take consumption as exogenous and mute international trade. In contrast, our main model establishes a tight relationship between the asset pricing moments presented in this section and interna- 
tional asset positions. Second, for the sake of tractability, our partial equilibrium model features exogenous time-varying volatility. In our recursive risk-sharing arrangement, instead, time-varying economic uncertainty is endogenous because of international trade.

Setup. The economy consists of $N$ countries. Each country $i$ is populated by a representative agent with Epstein and Zin (1989) recursive preferences. Without loss of generality, in this section we set the intertemporal elasticity of substitution to 1 and obtain

$$
U_{i, t}=(1-\delta) \log \left(C_{i, t}\right)+\delta \cdot \frac{1}{1-\gamma} \log \left(E_{t}\left[\exp \left((1-\gamma) U_{i, t+1}\right)\right]\right)
$$

where $C_{i, t}, \delta$, and $\gamma$ denote the consumption in country $i$ at date $t$, subjective discount factor, and risk aversion, respectively. When $\gamma \rightarrow 1$, these preferences collapse to time-additive preferences. ${ }^{3}$ We generalize our results to the case of an intertemporal elasticity of substitution different from 1 in the next section.

The logarithm of consumption growth in each country evolves according to the following law of motion:

$$
\begin{aligned}
& \Delta c_{i, t+1}=\mu_{c}+z_{i, t}+\sqrt{\sigma_{i, t}} \varepsilon_{i, t+1}^{c} \\
& z_{i, t}=\rho_{z} z_{i, t-1}+\varphi_{e} \sqrt{\sigma_{i, t-1}}\left(\varepsilon_{i, t}^{z}+\left(1+\beta_{i}\right) \cdot \varepsilon_{\text {global }, t}\right) \\
& \sigma_{i, t}=\left(1-\rho_{\sigma}\right) \bar{\sigma}_{i}+\rho_{\sigma} \sigma_{i, t-1}+\sqrt{\sigma_{\sigma}} \varepsilon_{i, t}^{\sigma}, \quad \forall i \in\{1,2, \ldots, N\}
\end{aligned}
$$

where $z_{i, t}$ represents the date $t$ expected growth rate of consumption growth in country $i$, and $\sigma_{i, t}$ denotes the date $t$ conditional variance of consumption growth rate in country $i$. The news to expected consumption growth rate are split into two components: $\varepsilon_{i, t}^{z}$ represents the local news, whereas $\varepsilon_{\text {global }, t}$ is the global component.

\footnotetext{
${ }^{3}$ Specifically, when $\gamma \rightarrow 1$ the utility function converges to $U_{i, t}=(1-\delta) \log \left(C_{i, t}\right)+\delta E_{t}\left[U_{i, t+1}\right]$.
} 
Consistent with our empirical analysis, countries are heterogeneous in their exposure to global news shocks, with $\beta_{i} \in(-1,1) \forall i \in\{1,2, \ldots, N\}$. We also assume that countries are heterogeneous with respect to the unconditional level of their volatility process $\left(\bar{\sigma}_{i}\right)$. To be consistent with our risk-sharing model, we let the coefficient $\bar{\sigma}_{i}$ be an increasing function of the country's exposure to news shocks $\left(\beta_{i}\right)$. This is a reduced form way of incorporating one of our general equilibrium outcomes: high-exposure countries are characterized by more risky consumption and utility profiles.

All shocks are i.i.d. standard normals. We assume that: i) all the shocks within a country are orthogonal to each other; ii) the correlations of consumption growth shocks are identical across country pairs (i.e. $\operatorname{corr}\left(\varepsilon_{i, t+1}^{c}, \varepsilon_{j, t+1}^{c}\right)=\bar{\rho}^{c}, \forall i, j$ ); iii) the correlations of local news shocks are orthogonal across countries (i.e. $\operatorname{corr}\left(\varepsilon_{i, t+1}^{z}, \varepsilon_{j, t+1}^{z}\right)=0$, $\forall i, j$ ); and iv) the correlations of volatility shocks are orthogonal across countries (i.e. $\left.\operatorname{corr}\left(\varepsilon_{i, t+1}^{z}, \varepsilon_{j, t+1}^{z}\right)=0, \forall i, j\right)$. In Appendix A, we generalize this framework to the case in which the correlation of volatility shocks is different from zero.

Carry Trade and Forward Premium Puzzle. We provide a joint characterization of the carry trade risk premium and the slope coefficient of the uncovered interest rate parity regression. Throughout this section, we refer to $\Delta e_{t+1}^{i, j}$ as the logarithm of the growth rate of the exchange rate between currencies of countries $i$ and $j$, and to $r_{i, t}-r_{j, t}$ as the difference of the logarithms of the risk-free rates between the same two countries.

We note that the unconditional average of the interest rate is equal to:

$$
E\left[r_{k}\right]=\mu_{c}-\log (\delta)-\left(\gamma-\frac{1}{2}\right) \bar{\sigma}_{k}
$$

for each country $k \in\{1,2, \ldots, N\}$ (see equations (A10)-(A12) in the Technical Appendix for the derivations). When $\gamma>1 / 2$, our assumption that $\beta_{i}>\beta_{j}$ is associated 
to $\bar{\sigma}_{i}>\bar{\sigma}_{j}$ implies that sorting countries from high to low $\beta$ is equivalent to sorting them from low to high using average interest rates. Equivalently, a standard unconditional carry trade strategy implies that high- $\beta$ countries represent the funding currencies, whereas low- $\beta$ countries represent the investing currencies.

We summarize our findings in the following two propositions. All details and proofs are reported in Appendix A.

Proposition 1 (Carry Trade Risk Premium). Let $R X_{t+1}^{k, i}=\exp \left\{\Delta e_{t+1}^{i, k}-r_{k, t}+r_{i, t}\right\}$ denote the excess return of the strategy that consists in borrowing in the currency of country $k$ and investing in the currency of country $i$. The unconditional cross-sectional spread between the excess return of the countries with the lowest exposure ("L") and highest exposure ("H") to the global long-run risk is:

$$
\begin{aligned}
E\left[\log E_{t}\left(R X_{t+1}^{k, L}\right)-\log E_{t}\left(R X_{t+1}^{k, H}\right)\right] & =E\left[H M L_{t}\right] \\
& =\left[(1-\gamma) B \varphi_{e}\right]^{2}\left(1+\beta_{k}\right) \sqrt{\bar{\sigma}_{k}}\left(\beta_{H} \sqrt{\overline{\sigma_{H}}}-\beta_{L} \sqrt{\bar{\sigma}_{L}}\right)
\end{aligned}
$$

where $B=\frac{\delta}{1-\delta \rho_{z}}$.

Proof. See page 56 in Appendix A.

Proposition 2 (Forward Premium Puzzle). The slope coefficient $\widehat{\beta}_{F P P}$ in the linear regression

$$
\Delta e_{t+1}^{i, j}=\widehat{\alpha}_{F P P}+\widehat{\beta}_{F P P}\left(r_{i, t}-r_{j, t}\right)+\widehat{\xi}_{t+1}
$$

is equal to

$$
\widehat{\beta}_{F P P}=1-\left(\gamma-\frac{1}{2}\right) \cdot\left[\beta_{\sigma, F P P}+\left(1+\frac{\left(\beta_{i}+\beta_{j}\right)}{2}\right) \cdot \beta_{\sigma, H M L}\right] \cdot \frac{\operatorname{Var}\left(\sigma_{i, t}-\sigma_{j, t}\right)}{\operatorname{Var}\left(r_{i, t}-r_{j, t}\right)},
$$


where

$$
\begin{aligned}
& \beta_{\sigma, F P P}=\left[\frac{\left(1+B^{2} \varphi_{e}^{2}\right)(1-\gamma)^{2}}{2}+\left(\gamma-\frac{1}{2}\right)\right] \\
& \beta_{\sigma, H M L}=\left(B \varphi_{e}\right)^{2}(1-\gamma)^{2} \cdot \frac{\sigma_{\sigma}}{1-\rho_{\sigma}^{2}} .
\end{aligned}
$$

and $B=\frac{\delta}{1-\delta \rho_{z}}$.

Proof. See page 59 in Appendix A.

Corollary 1 (Time-Additive preference). Let $\gamma \rightarrow 1$, then the regression coefficient $\widehat{\beta}_{F P P}$ in equation (6) is such that $\widehat{\beta}_{F P P} \in(0,1)$.

Proof. See page 60 in Appendix A.

Discussion. The analytical expressions featured in our two Propositions show that the carry trade risk premium (HML) and the violation of the uncovered interest rate parity (FPP) relationship are distinct phenomena in our setting. According to equation (5), the two key factors in determining a non-zero carry trade risk premium are: i) the heterogeneous exposure to global long run news (i.e., $\beta^{H} \neq \beta^{L}$, and ii) the ability of recursive preferences to price such news (i.e., $\gamma \neq 1$ ). Since we do not have any heterogeneity with respect to short-run shocks, a model with time additive preferences would not produce a carry trade premium. Time-varying volatility is not necessary to have a positive premium.

Focusing on the slope of the uncovered interest rate parity regression (i.e., equation (7)), we note that as long as the risk aversion coefficient $\gamma$ is larger that $1 / 2$, time-varying volatility is sufficient to produce a violation of the uncovered interest rate parity relationship, i.e., $\widehat{\beta}_{F P P} \leq 1$. The larger the risk aversion coefficient $\gamma$, the smaller, and eventually negative, $\widehat{\beta}_{F P P}$ gets. Note that this result can be obtained 
regardless of heterogenous exposure to global shocks. Corollary 1 highlights that recursive preferences are needed to produce a negative uncovered interest rate parity regression coefficient.

Taken together, these results reinforce the message of Lustig et al. (2011) that heterogeneity in exposure to a global risk factor is important to explain the carry trade, and the findings of Hassan and Mano (2014) that the carry trade risk premium and the violation of the uncovered interest rate parity represent different empirical facts.

We conclude this section by pointing out that recursive preferences are needed to account for both HML and FPP in our setting. Without recursive preferences news shocks are not priced and the average HML is equal to zero. Further, as documented in Corollary 1 , the regression coefficient $\widehat{\beta}_{F P P}$ cannot be negative as in the data. This observation motivates the general equilibrium model with recursive preferences and heterogeneous exposure to global long-run growth news that follows.

\section{The Economy}

The economy consists of $N$ countries, and $N$ goods, $\left\{X_{i}\right\}_{i=1}^{N}$. Agents' preferences are defined over consumption aggregates of the $N$ goods as follows.

Consumption aggregate. Let $x_{i, t}^{j}$ denote the consumption of good $j$ in country $i$ at date $t$. The consumption aggregates in the $N$ countries are

$$
C_{t}^{i}=\left(x_{i, t}^{i}\right)^{\alpha} \prod_{j \neq i}\left(x_{j, t}^{i}\right)^{\frac{1-\alpha}{N-1}} .
$$

The parameter $\alpha \in(0,1)$ captures the degree of bias of the consumption of each representative agent. In what follows we assume that each country $i$ receives a stochastic 
endowment of good $X_{i, t}$ at each point in time. Following some of the international macrofinance articles surveyed by Lewis (2011), we assume that $\alpha$ is larger than 0.5. This allows us to build consumption home bias into the model.

Preferences. As in Epstein and Zin (1989), agents' preferences are recursive but non-time-separable:

$$
U_{i, t}=\left[(1-\delta) \cdot\left(C_{i, t}\right)^{1-1 / \psi}+\delta E_{t}\left[\left(U_{i, t+1}\right)^{1-\gamma}\right]^{\frac{1-1 / \psi}{1-\gamma}}\right]^{\frac{1}{1-1 / \psi}}, \quad \forall i \in\{1, \ldots, N\}
$$

The coefficients $\gamma$ and $\psi$ measure the relative risk aversion (RRA) and the intertemporal elasticity of substitution (IES), respectively.

The main departure from the constant RRA case often analyzed in the literature lies in the fact that our model's preferences allow agents to be risk averse in future utility as well as future consumption. The extent of such utility risk aversion depends on the preference for early resolution of uncertainty measured by $\gamma-1 / \psi>0$. To better highlight this feature of the preferences, we note that the ordinally equivalent transformation

$$
V_{t}=\frac{U_{t}^{1-1 / \psi}}{1-1 / \psi}
$$

can be approximated as follows:

$$
\begin{aligned}
V_{t} & =(1-\delta) \frac{C_{t}^{1-1 / \psi}}{1-1 / \psi}+\delta E_{t}\left[V_{t+1}^{1-\theta}\right]^{\frac{1}{1-\theta}} \\
& \approx(1-\delta) \frac{C_{t}^{1-1 / \psi}}{1-1 / \psi}+\delta E_{t}\left[V_{t+1}\right]-\frac{\delta}{2} \frac{\theta}{E_{t}\left[V_{t+1}\right]} \operatorname{Var}_{t}\left[V_{t+1}\right]
\end{aligned}
$$

where $\theta \equiv \frac{\gamma-1 / \psi}{1-1 / \psi}$. Note that the sign of $\left(\frac{\theta}{E_{t}\left[V_{t+1}\right]}\right)$ depends on the sign of $(\gamma-1 / \psi)$. When $\gamma=1 / \psi$, the agent is utility-risk neutral and preferences collapse to the standard time-additive case. When the agent prefers early resolution of uncertainty, that 
is, when $\gamma>1 / \psi$, the coefficient $\theta$ is positive: uncertainty about continuation utility reduces welfare and generates an incentive to trade off future expected utility, $E_{t}\left[V_{t+1}\right]$, for future utility risk, $\operatorname{Var}_{t}\left[V_{t+1}\right]$. This mean-variance trade-off is an appealing feature of these preferences, and one that is absent when agents have standard time-additive preferences. This trade-off drives international allocations and exchange rate adjustments in our economy, and it represents the most important element of our analysis. Our study is the first to fully characterize trade with Epstein and Zin (1989) preferences in an economy composed by an arbitrary number of countries.

Since there is a one-to-one mapping between utility, $U_{i, t}$, and lifetime wealth, the optimal risk-sharing scheme can also be interpreted in terms of mean-variance tradeoff of wealth. For this reason, in what follows we will use the terms "wealth" and "continuation utility" interchangeably.

Endowments. We choose to endow each country with a stochastic supply of its most-preferred good. Endowments are cointegrated processes, and they feature predictive variables as follows:

$$
\log X_{t}^{i}=\mu_{x}+\log X_{t-1}^{i}+z_{i, t-1}-\tau\left[\log X_{t-1}^{i}-\frac{1}{N} \log \left(\sum_{j=1}^{N} X_{i, t}\right)\right]+\varepsilon_{i, t}^{X}
$$

where $\tau \in(0,1)$ determines the extent of cointegration, and the processes $z_{i}$ are modeled as highly persistent AR(1) processes,

$$
z_{i, t}=\rho_{i} z_{i, t-1}+\varepsilon_{i, t}^{z}, \forall i \in\{1,2, \ldots, N\}
$$

Throughout the paper, we refer to $\varepsilon_{i, t}^{z}$ as the long-run shocks, due to their long-lasting impact on the growth rates of the endowments. Similarly, we call $\varepsilon_{i, t}^{X}$ short-run shocks. 
Shocks are jointly log-normal. We abstract from exogenous time-varying volatility in endowments to better quantify the amount of endogenous consumption and assetprice volatility generated by our recursive risk-sharing mechanism with complete markets.

Heterogenous exposure. Consistent with our empirical investigation, we introduce cross-country variation in the exposure to global long-run endowment shocks, $\beta_{i, t}^{z}$. Since long-run shocks are the primary driver of our risk-sharing mechanism, this modeling choice produces no loss of generality. Specifically, in each country we decompose our long-run shocks $\left(\varepsilon_{i, t}^{z}\right)$ into a common global component and a country-specific component as follows:

$$
\varepsilon_{i, t}^{z}=\left(1+\beta_{i, t-1}^{z}\right) \epsilon_{g l o b a l, t}^{z}+\epsilon_{i, t}^{\tilde{z}},
$$

with the shocks to the two components being orthogonal to each other:

$$
\operatorname{corr}\left(\epsilon_{\text {global }, t}^{z}, \epsilon_{i, t}^{\tilde{z}}\right)=\operatorname{corr}\left(\epsilon_{i, t}^{\tilde{z}}, \epsilon_{f, t}^{\tilde{z}}\right)=0 .
$$

The volatilities of $\epsilon_{g l o b a l, t}^{z}$ and $\epsilon_{i, t}^{\tilde{z}}$ are set to replicate both the unconditional standard deviation and correlation of the long-run shocks, $\epsilon_{i, t}^{z}$, described in the previous section. Country-specific sensitivity coefficients are modeled as a slowly moving AR(1) process,

$$
\beta_{i, t}^{z}=\rho_{z}^{\beta} \beta_{i, t-1}^{z}+\epsilon_{i, t}^{\beta, z}
$$

with $\epsilon_{i, t}^{\beta, z} \sim$ i.i.d.N $\left(0, \sigma_{\beta, z}\right)$. These shocks are both long-lived $\left(\rho_{z}^{\beta} \approx 1\right)$ and uncorrelated to other shocks, as they are meant to approximate nearly unconditional differences in the exposure of countries to global news. Countries with high $\beta_{i, t}^{z}$ have relatively more risky endowments, in the sense that their local growth processes are more exposed to 
shocks to global long-run growth.

Our way to model country-specific exposure to shocks produces a twofold benefit. First of all, it enables us to study an economy with ex ante symmetrically calibrated countries for which a well-defined equilibrium exists (Colacito and Croce 2012). Second, after simulating a history of heterogenous exposure shocks $\left(\epsilon_{i, t}^{\beta, z}\right)$, we are able to study the characteristics of a cross section of countries that remain substantially heterogenous in finite samples. We think of the $\beta_{i, t}^{z}$ coefficients as devices to capture the heterogeneity documented by Lustig et al. (2011), Backus et al. (2010), Ready et al. (2012), and Hassan and Mano (2014) in a parsimonious, reduced-form manner.

Market structure. At each date, agents trade a complete set of state-contingent one-period-ahead claims to the numeraire good. Without loss of generality, we choose good 1 as our numeraire. Since both financial and goods markets are assumed to be frictionless, the budget constraint of our agents can be written as

$$
\sum_{j=1}^{N} p_{j, t} x_{i, t}^{j}+\int_{\zeta^{t+1}} A_{i, t+1}\left(\zeta^{t+1}\right) Q_{t+1}\left(\zeta^{t+1}\right)=A_{i, t}+p_{i, t} X_{i, t}
$$

where $p_{i, t}$ denotes the price of good $i$ relative to that of good one, $A_{i, t}\left(\zeta^{t}\right)$ denotes country $i$ 's claims to time $t$ consumption of good $X_{1}$, and $Q_{t+1}\left(\zeta^{t+1}\right)$ gives the price of one unit of time $t+1$ consumption of good $X_{1}$ contingent on the realization of $\zeta^{t+1}$ at time $t+1$. In equilibrium, the market for international state-contingent claims clears, implying that $\sum_{i} A_{i, t}=0, \forall t$.

Allocations. Since markets are complete, we can compute efficient allocations by solving the associated Pareto problem. The planner attaches date 0 nonnegative Pareto weights $\left\{\mu_{i}\right\}_{i=1}^{N}$ to the consumers and chooses the sequence of allocations $\left\{x_{i, t}^{j}\right\}_{t=0}^{+\infty}$, 
$\forall i$ and $j \in\{1, \ldots, N\}$ to maximize

$$
\Lambda=\sum_{i=1}^{N} \mu_{i} \cdot U_{i, 0},
$$

subject to the following sequence of economy-wide feasibility constraints:

$$
\sum_{j=1}^{N} x_{i, t}^{j}=X_{i, t}, \quad \forall t \geq 0 \quad \text { and } \quad \forall i \in\{1, \ldots, N\}
$$

where the state-dependent notation is omitted for the sake of clarity. In characterizing the equilibrium, we follow Anderson (2005) and Colacito and Croce (2013) and formulate the problem using the ratio of time-varying pseudo-Pareto weights, $S_{j, t}=\mu_{j, t} / \mu_{1, t}$, as an additional state variable. This technique enables us to take into account the nonseparability of the utility functions. We show in the Appendix that the first-order necessary conditions imply the following allocations:

$$
\begin{aligned}
& x_{i, t}^{i}=\left(1+\frac{1-\alpha}{\alpha(N-1)} \sum_{j \neq i} \frac{S_{j, t}}{S_{i, t}}\right)^{-1} X_{i, t}, \quad \forall i \in\{1,2, \ldots, N\} \\
& x_{i, t}^{j}=\frac{1-\alpha}{\alpha} \frac{1}{N-1} \frac{S_{j, t}}{S_{i, t}} x_{i, t}^{i}, \quad \forall i \neq j \in\{1,2, \ldots, N\}
\end{aligned}
$$

where

$$
S_{j, t}=S_{j, t-1} \cdot \frac{M_{j, t}}{M_{1, t}} \cdot\left(\frac{C_{j, t} / C_{j, t-1}}{C_{1, t} / C_{1, t-1}}\right), \quad \forall t \geq 1
$$

and $S_{j, 0}=1$, as we start the economy from an identical allocation of wealth and endowments. This is consistent with the ergodic distribution of the model, which implies that on average all countries consume an identical share of world resources because of symmetry.

Prices. The stochastic discount factor that is used to discount future uncertain pay- 
offs is

$$
M_{i, t+1}=\delta\left(\frac{C_{i, t+1}}{C_{i, t}}\right)^{-\frac{1}{\psi}}\left(\frac{U_{i, t+1}^{1-\gamma}}{E_{t}\left[U_{i, t+1}^{1-\gamma}\right]}\right)^{\frac{1 / \psi-\gamma}{1-\gamma}} .
$$

Since markets are assumed to be complete, the log growth rate of the real exchange rate between the consumption bundles of countries $i$ and $j$ is

$$
\Delta e_{i, t}^{j}=\log M_{j, t}-\log M_{i, t}
$$

and the relative price of good $j$ and good 1 is $p_{j, t}=\frac{(1-\alpha)}{\alpha(N-1)} \frac{x_{1, t}^{1}}{x_{j, t}^{1}}$.

Bilateral imports and exports. At each point in time, the exports of country 1 toward country $j$ are equal to $E X P_{1, t}^{j}=x_{j, t}^{1}$, and the imports of country 1 from country $j$ are equal to $I M P_{1, t}^{j}=p_{j, t} x_{1, t}^{j}$, where $x_{j, t}^{1}, p_{j, t}$, and $x_{1, t}^{j}$ are defined above. It follows that the bilateral volume of trade and the bilateral net exports rescaled by total output are equal to

$$
\frac{V o l_{1, t}^{j}}{X_{1, t}}=\frac{(1-\alpha) \cdot\left(1+S_{t}^{j}\right)}{\alpha(N-1)+(1-\alpha) \sum_{j \neq 1} S_{t}^{j}}
$$

and

$$
\frac{N X_{1, t}^{j}}{X_{1, t}}=\frac{(1-\alpha) \cdot\left(S_{t}^{j}-1\right)}{\alpha(N-1)+(1-\alpha) \sum_{j \neq 1} S_{t}^{j}},
$$

respectively. Detailed derivations are reported in the Appendix.

\subsection{Calibration and Solution Method}

We detail our baseline monthly calibration in Table 2 . We choose a monthly frequency to be consistent with the empirical methods adopted in the carry-trade literature. When possible, our parameters are chosen to be the monthly counterpart of our an- 
nual estimates.

All preference parameters are set in the spirit of the long-run risk literature (see Bansal and Yaron 2004, Bansal et al. 2010, and Colacito and Croce 2013). The parameters governing the dynamics of the growth rates of the endowments are chosen to reflect an average annual growth rate of $2 \%$, an unconditional volatility of $2 \%$, and a modest degree of autocorrelation. These moments are set to be consistent with the median values in our data set and are discussed further in the next section.

We choose to calibrate the cross-country correlation of the short-run shocks to a low level, so that the model is consistent with the moderate cross-country correlation of consumption growth rates across major industrialized countries. Under the benchmark calibration with heterogenous exposure, this correlation is set to 0.40 , a number that falls in the middle of the correlation range estimated among our ten countries. When we consider the special setting without heterogenous exposure, we set this parameter to a slightly smaller number, 0.20 , to prevent the consumption profiles from being excessively correlated. Both parameter values are consistent with other studies in the international macroeconomics literature.

We set the cross-country correlation of the long-run components to 0.93 , as the growth rates of major countries are highly correlated over the long horizon (see, among others, Colacito and Croce 2011). This finding holds also in our data, as our results show that the correlation of our long-run components can be as high as 0.95. Both the amount of long-run risk $\left(\sigma_{z} / \sigma\right)$ and the persistence of the long-run components $(\rho)$ are consistent with the empirical estimates reported in Table 1.

We set $\rho_{z}^{\beta}=.999$ to create nearly permanent heterogeneity in exposure to world output shocks. We choose $\sigma_{\beta, z}=0.05 \%$ to obtain a very moderate conditional volatility of our exposure parameters. Consistent with our empirical results, in the short sample the 
TABLE 2: Calibration

\begin{tabular}{lc}
\hline \hline Description & Values \\
\hline Preferences: & \\
Relative Risk Aversion $[\gamma]$ & 6.50 \\
Intertemporal Elasticity of Substitution $[\psi]$ & 1.60 \\
Subjective Discount Factor $\left[\delta^{12}\right]$ & 0.98 \\
Degree of Home Bias $[\alpha]$ & 0.98 \\
Endowments: & \\
Mean of Endowment Growth $(\%)[12 \mu]$ & 2.00 \\
Short-Run Risk Volatility $(\%)[\sigma \sqrt{12}]$ & 1.87 \\
Long-Run Risk Volatility $(\%)\left[\sigma_{z} / \sigma\right]$ & 6.00 \\
Long-Run Risk Autocorrelation $(\%)\left[\rho^{12}\right]$ & 0.78 \\
Cross-Correlations of Long-Run Shocks $\left[\rho_{z}\right]$ & 0.93 \\
\hline
\end{tabular}

\begin{tabular}{lcc} 
& \multicolumn{2}{c}{ Exposure } \\
\cline { 2 - 3 } & Homogenous & Heterogenous \\
\hline Cross-Correlations of Short-Run Shocks $\left[\rho_{X}\right]$ & 0.20 & 0.40 \\
Orthogonalization: & & 5.80 \\
Volatility of Global Long-Run Shocks $(\%)\left[\sigma_{z}^{\text {global }} / \sigma\right]$ & - & 1.60 \\
Volatility of Local Long-Run Shocks $(\%)\left[\sigma_{z}^{\text {global } / \sigma]}\right.$ & - & \\
Time-Varying Exposure: & & 0.99 \\
Autocorrelation of $\beta_{i, t}^{z}\left[\left(\rho_{z}^{\beta}\right)^{12}\right]$ & - & 0.05 \\
Volatility of Shocks to $\beta_{i, t}^{z}(\%)\left[\sigma_{\beta, z}\right]$ & - & \\
\hline
\end{tabular}

Notes - This table reports our benchmark monthly calibration. Under the homogeneous exposure case, $\beta_{i, t}^{z}=1 \quad \forall i, \forall t$.

time-variation of our exposure coefficients is statistically undetectable.

Given these parameters, we use perturbation methods to solve our system of equations. We compute an approximation of the third order of our policy functions using the dynare++ package. As documented in Colacito and Croce (2012, 2013), a third-order approximation is required to capture endogenous time-varying volatility due to the adjustments of the pseudo-Pareto weights. ${ }^{4}$ All variables included in our dynare++ code are expressed in log-units.

\footnotetext{
${ }^{4}$ For additional details concerning the solution and the approximation of recursive economies with multiple agents see Rabitsch et al. (2015).
} 


\section{The Cross Section of Currency Risk Premia}

In this section, we study the main moments produced by a recursive risk-sharing scheme with multiple countries. We start from a setting with homogeneous exposure to news shocks and show that the resulting allocation dynamics are broadly consistent with the data. Most importantly, we show that a recursive risk-sharing scheme cannot produce the observed returns of a carry-trade strategy, even though it endogenously accounts for the forward premium anomaly. This limitation is resolved in section 5.2 by introducing heterogenous exposure to global long-run shocks. In section 5.3, we show novel empirical evidence that supports the distinctive channels at work in our model.

\subsection{Homogeneous exposure.}

We set the number of countries in our model to be five, a figure large enough to form a proper cross-section of currency portfolios and small enough to keep our computations feasible. We report the resulting main moments usually studied in international macrofinance in Table 3. In Appendix C, we show that most of these moments are not sensitive to the number of countries, implying that our results are quite general. We also characterize the behavior of common measures of risk-sharing as we increase the number of countries. Since most of our findings replicate those in the two-country economy of Colacito and Croce (2013), we defer the inspection of the mechanism of the model with homogeneous exposure to Appendix C. In what follows we briefly highlight the successes and limitations of this setting.

Successes. With homogeneous exposure to global news shocks, our model produces consumption dynamics very close to the data. This is true for both within-country and 
cross-country moments. Thanks to the presence of highly cross-country correlated long-run growth news, stochastic discount factors are volatile and highly correlated across countries even though consumption growth rates are not. As a result, the exchange rate growth volatility is not subject to the Brandt et al. (2006) puzzle.

This setting produces low and smooth risk-free rates. Across countries, the risk-free rates are as highly correlated as the stochastic discount factors. Furthermore, the volatility of the net foreign asset position in each country is consistent with the data, since recursive preferences and long-run growth news make the valuation channel as strong as in the data (see Gourinchas and Rey 2013 and Colacito and Croce 2013). In Appendix C, we show that the model can also account for the almost complete lack of correlation between consumption growth differentials and exchange rate fluctuations (cf. Backus and Smith 1993 puzzle). This is the result of the opposite response of consumption growth differentials to short- and long-run shocks already documented in Colacito and Croce (2013).

As in Colacito and Croce (2013), the model is able to produce a negative slope of the uncovered interest rate parity regressions $\left(\beta_{U I P}\right)$. In the presence of local news shocks, agents with recursive preferences are willing to swap current consumption for smoother future consumption profiles. As a result, agents implement a trade of securities that produces sizable endogenous time-varying volatility. As shown in section 3 , this is a sufficient condition to have a negative $\beta_{U I P}$.

Limitations. We conclude our quantitative analysis by noting the inability of the model to produce a sizeable risk premium in the cross section of risk-free rate-sorted currencies $(E[H M L])$. In a model with recursive preferences, the distribution of wealth or, equivalently, pseudo-Pareto weights $\left(S_{i, t}\right)$, is an endogenous state variable that drives allocations and prices. Because of risk-aversion and home-bias, the opti- 
mal policy is non-linear and the response to news shocks changes with the distribution of wealth.

In Figure 1, we show the response to global shocks of countries that have same endowment but different wealth. At the equilibrium, this is possible because of the arrival of different local news shocks. Specifically, country 1 is assumed to have received better local long-run news than country 5 . Because of higher expected growth, country 1 has higher interest rate. Because of risk-sharing, country 1 must transfer resources to country 5 , i.e., country 1 has a negative NFA position. The strategy that goes long the currency of country 1 (high interest rate country) and shorts the currency of country 5 (low interest rate country) produces a negligible carry trade discount of $-0.02 \%$, a number well below the empirical premium of $3 \%$.

\subsection{Heterogeneous exposure}

In this section, we show that accounting for persistent heterogeneity in the exposure to world news shocks can produce sizeable cross-sectional currency premia. Furthermore, our model produces equivalent results when sorting countries on (i) nearly permanent heterogenous exposure to endowment shocks (Lustig et al. 2011, Hassan and Mano 2014), (ii) net foreign asset positions (Della Corte et al. 2013), or (iii) the level of their risk-free rate (Lustig et al. 2011).

Conditional heterogeneity. We introduce time variation in the exposure of our five countries and initialize our economy so that country 1 has an exposure of 0.65 and country 5 has an exposure of -0.65 , a plausible range given our results from Panel B of Table 1. All other countries have an exposure coefficient equally spaced in this range. 

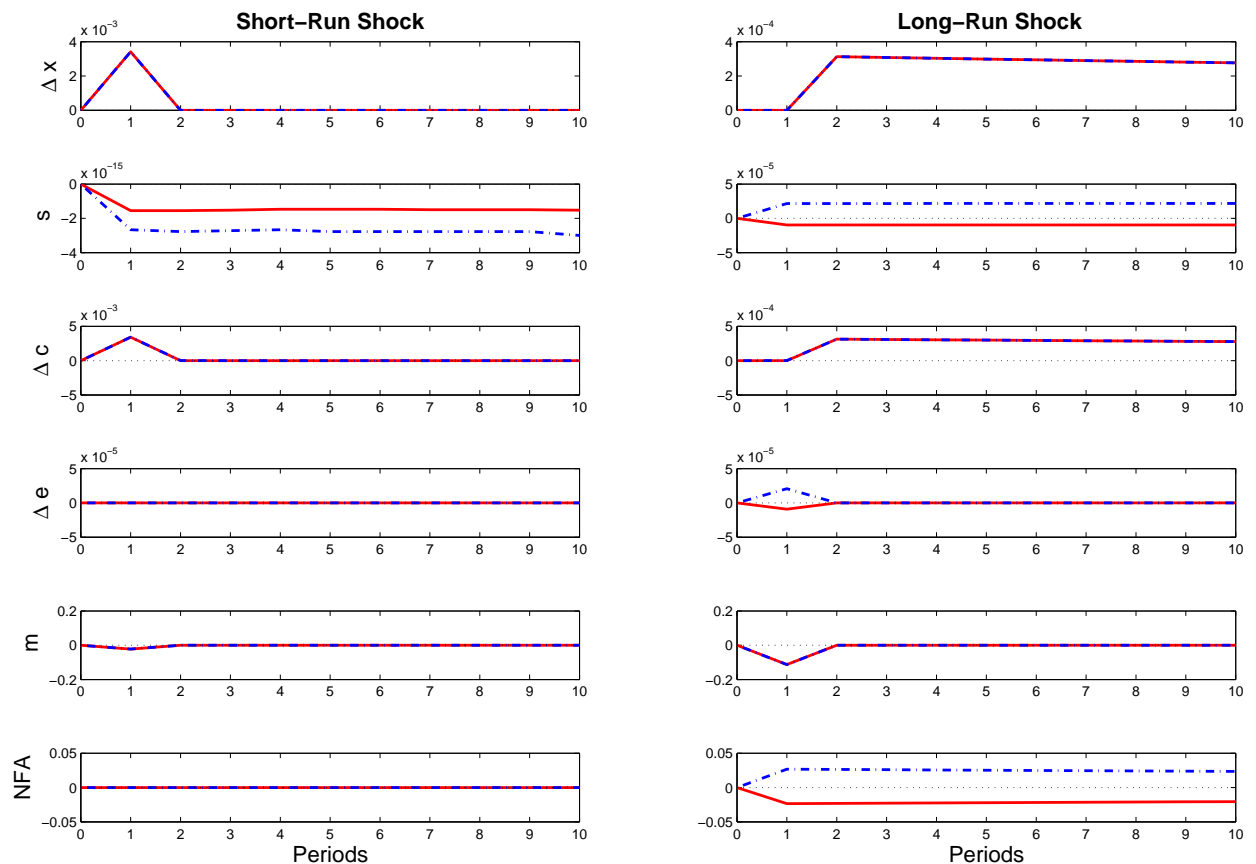

$-\mathrm{C} 1 \cdot-\cdot \mathrm{C} 5$

FIG. 1 - Impulse response functions under heterogenous wealth. The left (right) panels report the response of endowment growth $\left(\Delta \log X^{i}\right)$, relative Pareto weights with respect to country $3\left(\log S_{j} / S_{3}\right)$, consumption growth $\left(\Delta c_{i}\right)$, exchange rate growth $\left(\Delta e_{3}^{i}\right)$, stochastic discount factors $\left(m_{i}\right)$, and net foreign assets $\left(A_{i} / X_{i}\right)$ to a one-standard-deviation short-run (long-run) global shock. All panels refer to the case in which the economy consists of 5 countries $(i=1, \ldots, 5)$. The exchange rate is measured with respect to country 3 , implying that $\Delta e<0$ for country 1 denotes a depreciation of its real exchange rate with respect to country 3. Country 1 (5) is initialized with a positive (negative) NFA. Exposure to global news shocks is assumed to be homogeneous.

In order to reach this cross section of exposure values, we create a burn-in simulation period in which we give a sequence of positive (negative) exposure shocks to countries 1 and 2 (4 and 5), and no exposure shock to country 3. All results presented in this section are obtained from repetitions of small samples with a number of monthly periods consistent with the empirical data set. All repetitions start from the same initial cross section of exposure coefficients.

In our setting, all countries are risk averse and buy insurance against shocks that increase their exposure to long-run world growth news. Along our burn-in simulation path, country 1 is by construction the country that experiences the most adverse 
sequence of exposure shocks. As a result of its financial portfolio allocation strategy, this country accumulates wealth against the rest of the world, i.e., it acquires a positive net foreign asset position. Furthermore, high risk exposure induces stronger precautionary saving motives, and hence it lowers the interest rate. As a result, in our simulated samples country 1 is a net lender with a low risk-free rate, whereas country 5 is a net borrower with a high interest rate (Della Corte et al. 2013). From a qualitative point of view, no additional financial frictions are required to obtain this sorting.

The positive link between average NFA positions and exposure to the long-run news shocks can also be explained by solving forward the budget constraint in (13):

$$
\begin{aligned}
A_{i, t} & =\left[\sum_{j=1}^{N} p_{j, t} x_{i, t}^{j}-p_{i, t} X_{i, t}\right]+\int_{\zeta^{t+1}} Q_{t+1}\left(\zeta^{t+1}\right) \cdot A_{i, t+1}\left(\zeta^{t+1}\right) \\
& =-\sum_{k=0}^{\infty} \mathcal{M}_{t+k} \cdot N X_{i, t+k}
\end{aligned}
$$

where $\mathcal{M}_{t+k}=\prod_{l=0}^{k} Q_{t+l}$ and $N X_{i, t+k}=\sum_{j=1}^{N} p_{j, t} x_{i, t}^{j}-p_{i, t} X_{i, t}, \forall i \in\{1, \ldots, N\}$. The NFA of a country tracks the present value of future promised transfers. In computing this expected present value, agents with a preference for early resolution of uncertainty assign stronger weight to states of the world in which negative global news shocks are realized. That is, negative global news shocks are the main determinant of the NFA positions. The trade balance of a low-exposure country improves in response to a negative global long-run shock: because of risk-sharing, it must transfer resources to countries with high exposure. This means that countries with low exposure are expected to predominantly have positive net exports in the future. As a result, their average NFA position is negative. By the same argument, high-exposure countries must have positive NFA on average.

In what follows, we think of countries 1 and 5 as Switzerland and Australia, re- 
spectively. These countries are representative of the two legs of the carry trade. By construction, country 3 represents the median country.

Response to global shocks. In Figure 2 we show the impulse response of our variables of interest for countries 1 and 5 with respect to global shocks. These impulse responses are created after our burn-in simulation sample, i.e., at time zero, country 1 has an exposure of +0.65 , whereas country 5 has an exposure of -0.65 .

With respect to global short-run shocks, both the consumption growth rate and stochastic discount factor adjust within each country as they would in a one-country economy. Since the exposure to global short-run shocks is the same for all countries, these shocks produce no international reallocation of resources. As a result, exchange rates do not move, and hence they feature zero exposure to global short-run risk. On this dimension the model is similar to many canonical models of exchange rates featuring symmetric countries and local shocks (e.g. Obstfeld and Rogoff 1995). As in the previous section, short-run global risk prescribes a null average return to the carry-trade strategy.

In contrast to short-run shocks, global long-run news shocks promote relevant international reallocations and generate currency risk. Specifically, upon the arrival of good news, the most exposed country (country 1) gets better relative news and features the lowest marginal utility. This adjustment causes two effects. First, by risk sharing, the net foreign asset position of country 1 deteriorates. In the next section, we show that the direction of these responses is consistent with that observed in our data set. Second, by no arbitrage, the real exchange rate of country 1 immediately depreciates, whereas the opposite is true for country 5 . Since all countries experience a drop in the marginal utility, the HML-FX carry-trade strategy (going long in country 5 and short in country 1 ) is risky, as it pays high excess returns in good states of 

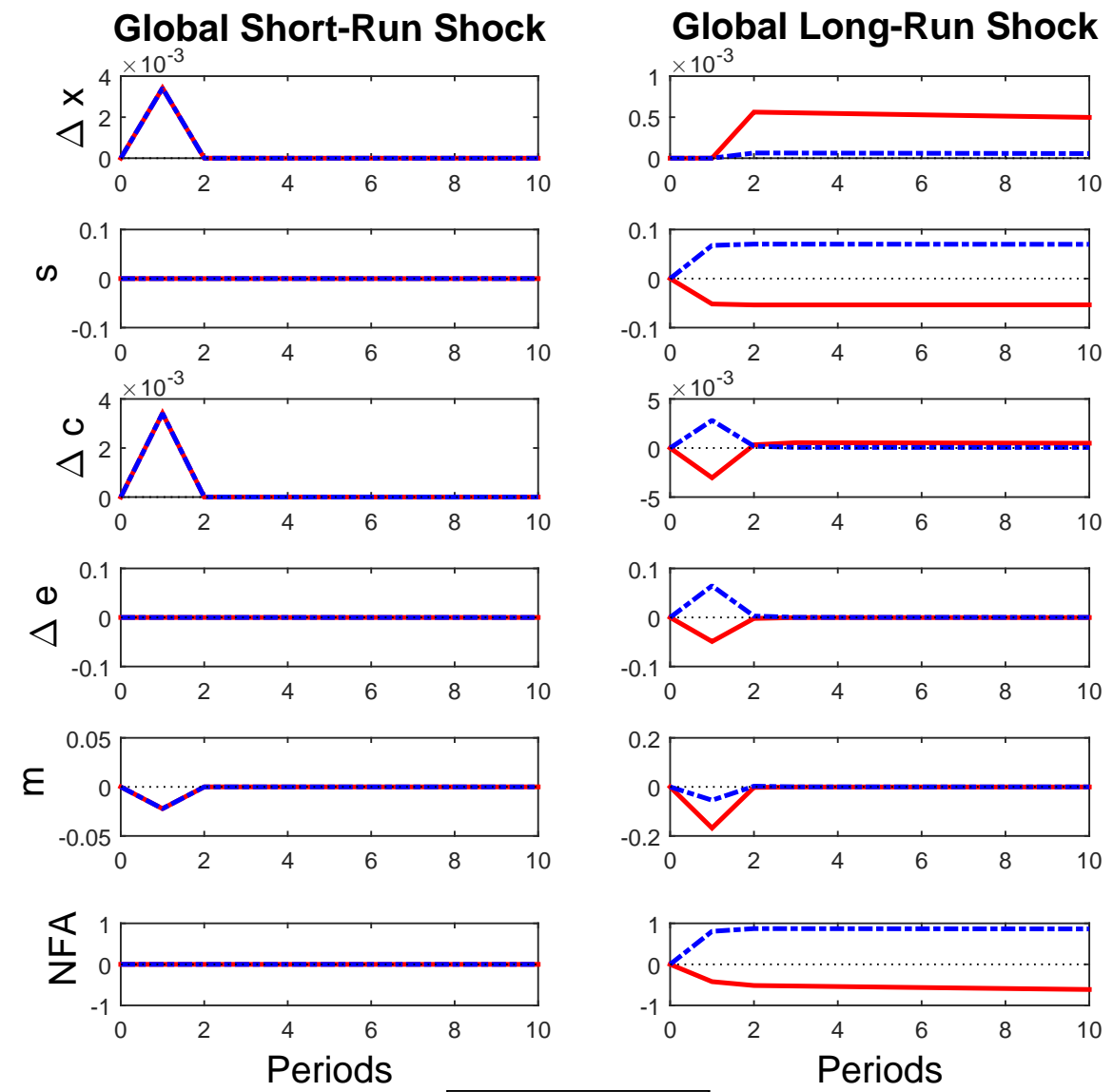

C1 --・-・C5

FIG. 2 - Impulse response functions under heterogenous exposure. The left (right) panels report the response of endowment growth $\left(\Delta \log X^{i}\right)$, relative Pareto weights with respect to country $3\left(\log S_{j} / S_{3}\right)$, consumption growth $\left(\Delta c_{i}\right)$, exchange rate growth $\left(\Delta e_{3}^{i}\right)$, stochastic discount factors $\left(m_{i}\right)$, and net foreign assets $\left(A_{i} / X_{i}\right)$ to a one-standard-deviation short-run (long-run) global shock. All panels refer to the case in which the economy consists of 5 countries $(i=1, \ldots, 5)$. The exchange rate is measured with respect to country 3 , implying that $\Delta e<0$ for country 1 denotes a depreciation of its real exchange rate with respect to country 3 . Country 1 (5) is initialized with an exposure to long-run shocks of $0.65(-0.65)$.

the world.

To better explain this result, in Figure 3 we report key characteristics of our countries. The top panel shows the country-specific exposure to global output shocks, as defined in equation (2). Consistent with our empirical findings, our countries have similar exposure to global output growth shocks since by construction their exposure to shortrun shocks is constant in the cross section. The second panel shows our distribution 


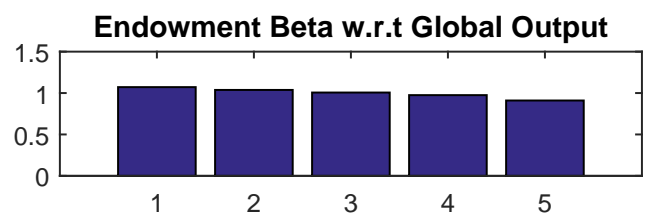

LR Endowment Beta w.r.t Global LR Shock
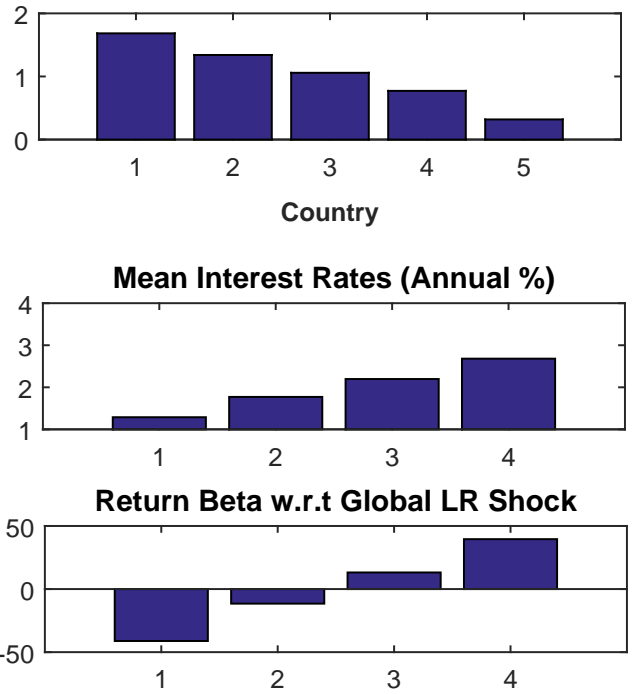

Return Beta w.r.t HML Factor

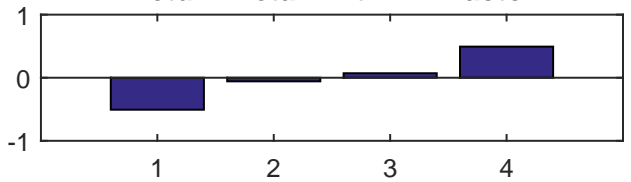

Mean Portfolio Returns (Annual \%)

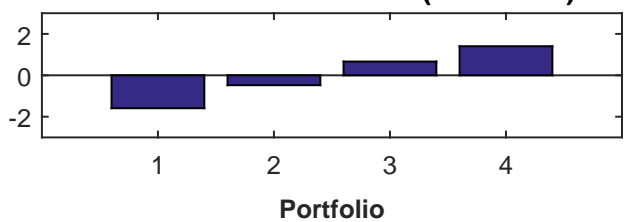

FIG. 3 - Cross-Sectional Risk (EZ Case). The top panel shows the the exposure of our five countries to global output $\left(1+\beta_{\Delta y}^{i}\right)$ as defined in equation (2). The second panel depicts their exposure to the global long-run component $\left(1+\beta_{i}^{z}\right)$. The bottom four panels show the cross-sectional characteristics of four portfolios formed by sorting our countries each period on their lagged interest rate differential with respect to a fixed numeraire country (country 3 ). All the parameters are calibrated to the monthly values reported in Table 2. Statistics are the averages across 300 simulations of 250 monthly observations.

of long-run risk exposure coefficients $\left(1+\beta_{i}^{z}\right)$, i.e., our main driver of cross-sectional heterogeneity. 
The remaining panels refer to four currency portfolios created as follows. Without loss of generality, we select the median country (country 3) as numeraire and focus on the remaining four bilateral exchange rates to form four currency portfolios sorted on interest rate differentials, $i_{j, t}-i_{3, t}$ with $j \neq 3$. The portfolio formation allows for frequent rebalancing, but due to the persistent differences in exposure to global longrun risk the transition of countries across different portfolios is infrequent. That is, portfolio 4 almost always corresponds to country 5 , whereas portfolio 1 coincides with the riskiest country, i.e., country 1 .

As already pointed out, because of precautionary saving motives there is an inverse relationship between a country's exposure to global long-run news and the average level of its own risk-free rate (Panel 3 of Figure 3). The high endowment-beta countries have low currency betas, i.e., their currencies depreciate in global good times, consistent with the impulse response of the country 1 exchange rate (Panel 4). This mechanism is sufficient to generate a cross section of loadings on currency returns to the HML-FX factor that is consistent with the data (Panel 5). The implied average currency returns have an annual spread of about 3\% (bottom panel), consistent with the estimated unconditional HML-FX of Lustig et al. (2011). Given the absence of country turnover across portfolios, the unconditional HML-FX is the appropriate empirical counterpart of our currency risk premium.

The role of heterogeneity for median moments. In Table 3, we report simulated moments from our model with and without heterogenous exposure and recursive preferences. In all cases, we report median values from our cross section of 5 countries. In the absence of heterogenous exposure (first column), the moments are identical to those obtained in the last column of Table C1.

All moments remain basically unchanged across columns, implying that the introduc- 
TABLE 3: Simulated Moments

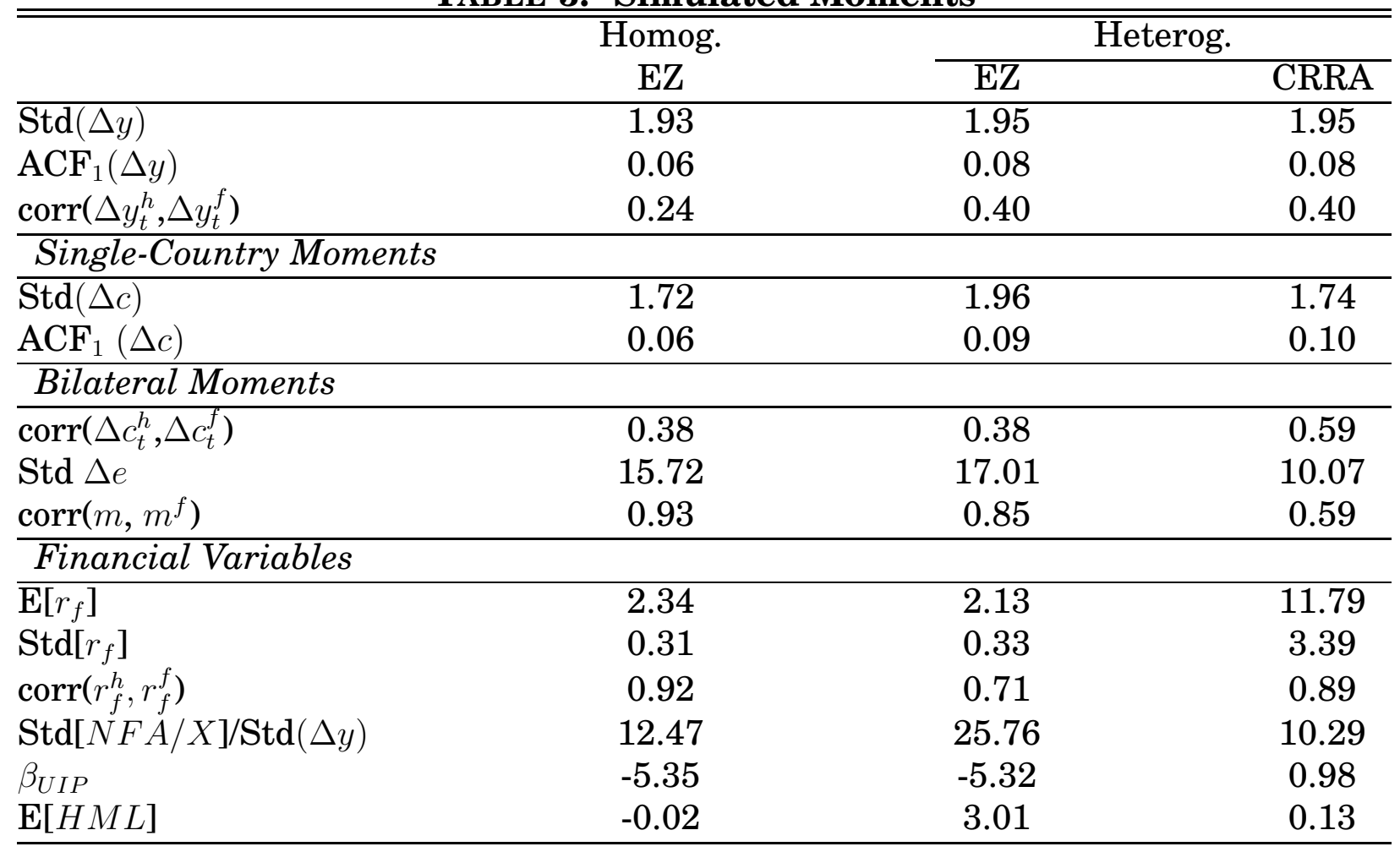

Notes - The table reports annualized simulated moments from the model with both heterogenuos and homogeneous exposure. All parameters are set to their benchmark values reported in Table 2. For the CRRA case, we set $\psi=1 / 6.5$. The first panel reports the moments for the dynamics of exogenous endowments' growth rates. The panel labeled "Single-Country Moments" reports the moments of the consumption growth rate within each country. The panel labeled "Bilateral Moments" reports the cross-country moments for each country pair. The panel labeled "Financial Variables" reports the moments for the risk-free rates $\left(r_{f}\right)$, net foreign assets to output ( $N F A$ ), slope coefficient of the UIP regressions $\left(\beta_{U I P}\right)$, and average currency risk premium (E[HML]).

tion of heterogenous exposure does not undermine the basic successes of our model. We highlight just three differences. First, this configuration of the model is able to replicate both the forward premium anomaly and the unconditional HML observed in the data.

Second, heterogeneity introduces more cross-country variation in the exposure to shocks and hence reduces the correlation of the stochastic discount factors. As a result, the volatility of the bilateral exchange rate of the median country is slightly higher than that obtained under homogeneous exposure. 
Lastly, heterogeneity increases the risk-sharing motives and makes the adjustment of the net foreign asset positions more severe. This explains why with recursive preferences the volatility of the net foreign position almost doubles. We regard this result as a success, as it would be easily reduced by the introduction of realistic trading frictions, such as shipping costs (see, among others, Ready et al. 2012).

The role of preferences. Since in the next section we study in detail the crosssectional properties of our model, we conclude this part of our analysis by showing the results for the special case in which we set IES $=1 / \mathrm{RRA}=1 / 6.5$, i.e., the CRRA configuration. Figure 4 and the last column of Table 3 document that a number of counterfactual results arise in this particular setup.

First, we compute measures of consumption exposure to both global output growth shocks and long-run shocks. Since long-run news shocks are not directly priced and produce no immediate movements in the marginal utilities of our countries, there is no significant reallocation. As a result, the consumption growth betas with respect to long-run news are zero across all countries, even though their endowment growth exposures continue to be heterogenous.

Second, the amount of financial trade in the economy is much more limited than before, as documented by (i) the counterfactually moderate spread in the average net foreign asset positions of our five countries (left column, bottom panel), and (ii) the reduced volatility of the net foreign asset positions. Furthermore, with this particularly low value of the IES, the risk-free rates are too high (Weil 1989) and basically constant across countries (left column, second panel from the bottom). As a consequence, the average returns on currency portfolios sorted according to interest rate differentials have an irregular pattern. The same statements apply to the exposure of currency portfolio returns with respect to both global long-run shocks and the HML 

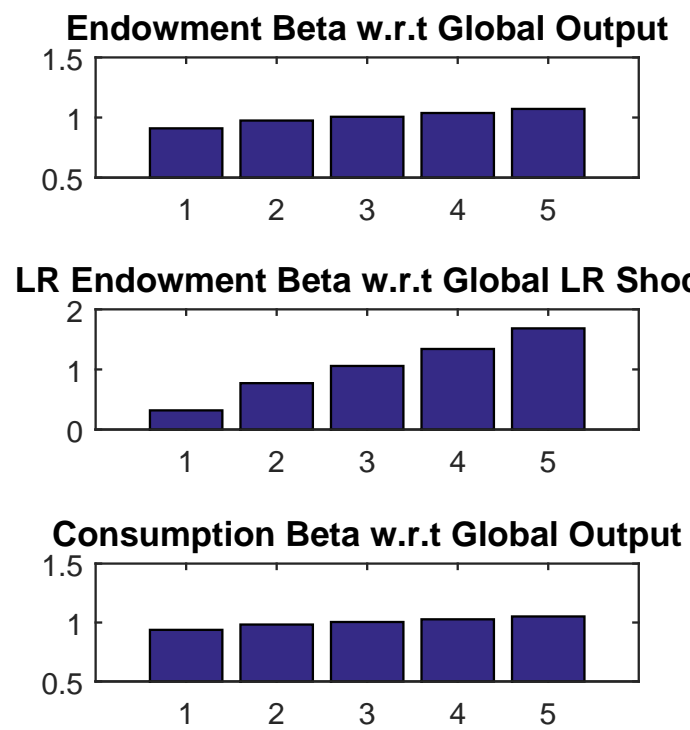

Consumption Beta w.r.t Global LR Shock
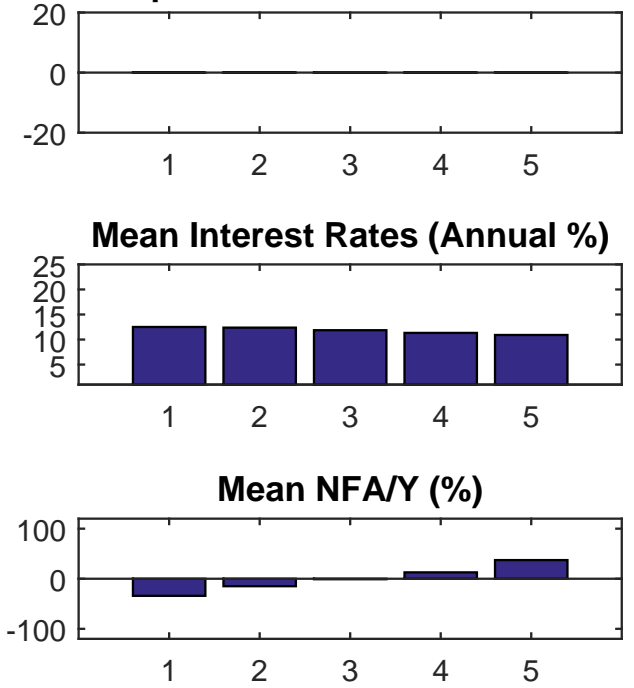
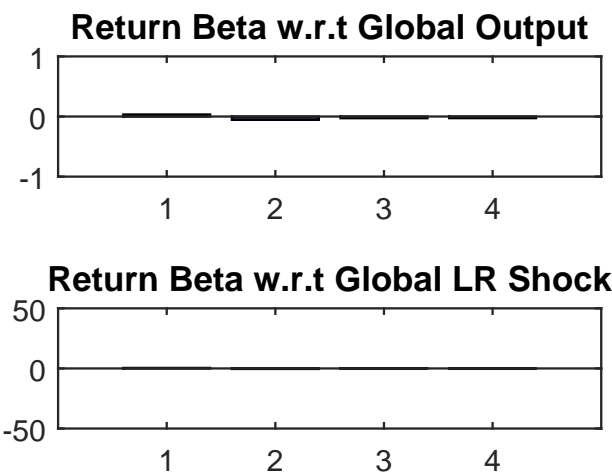

Return Beta w.r.t HML Factor

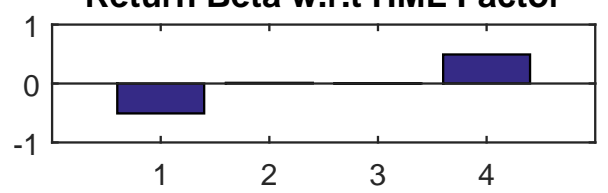

Mean Portfolio Returns (Annual \%)
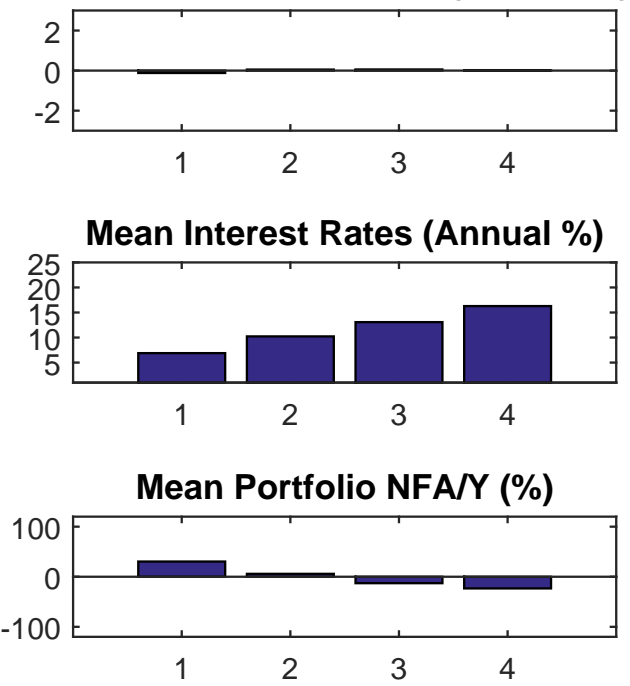

FIG. 4 - Cross-Sectional Risk (CRRA Case). The panels on the left show the crosssectional characteristics of five countries sorted on their exposure to the global long-run shock $\left(1+\beta_{i}^{z}\right)$. The panels on the right show the cross-sectional characteristics of four portfolios formed by sorting our countries each period on their lagged interest rate differential with respect to a fixed numeraire country. All the parameters are calibrated to the monthly values reported in Table 2, except the IES, which is set to $1 / 6.5$, the inverse of the risk aversion coefficient. Statistics are the averages across 100 simulations of short samples (360 monthly observations). 
factor.

Summarizing, long-run global growth news shocks can be an important driver of multiple phenomena in the cross section of currency, provided that agents price them directly. Epstein and Zin (1989) preferences enable news shocks to be priced and generate a recursive risk-sharing scheme that can explain key features of trade and international asset prices both at a country-pair level and in the cross section of countries. In the next section, we propose evidence supporting a number of implications of our frictionless model. In several relevant dimensions, the quantitative performance of the model is surprisingly close to the data.

\subsection{Evidence of qualitative predictions of the model}

In this section, we provide direct empirical evidence supporting the implications of our model for several aggregates of interest.

In Figure 5, we assess the ability of our model to replicate the cross section of currency and equity returns. In each panel, we report the data values for the cross section of countries that we employ in our empirical investigation (dots), a linear of the data (dashed lines), and the model's predictions (thick lines). Consistent with our previous simulation results, a carry trade strategy based on differences in exposure to long-run growth news can produce a premium comparable to that observed in our data (top-left panel).

Furthermore, our model performs well in replicating the joint distribution of currency and equity risk across countries. As in the data, countries with higher exposure to global growth news have both higher local returns (top-right panel) and higher excess returns (bottom-right panel). In contrast, the cross section of equity returns from the perspective of a US-based investor is close to flat both in the data and in our model 

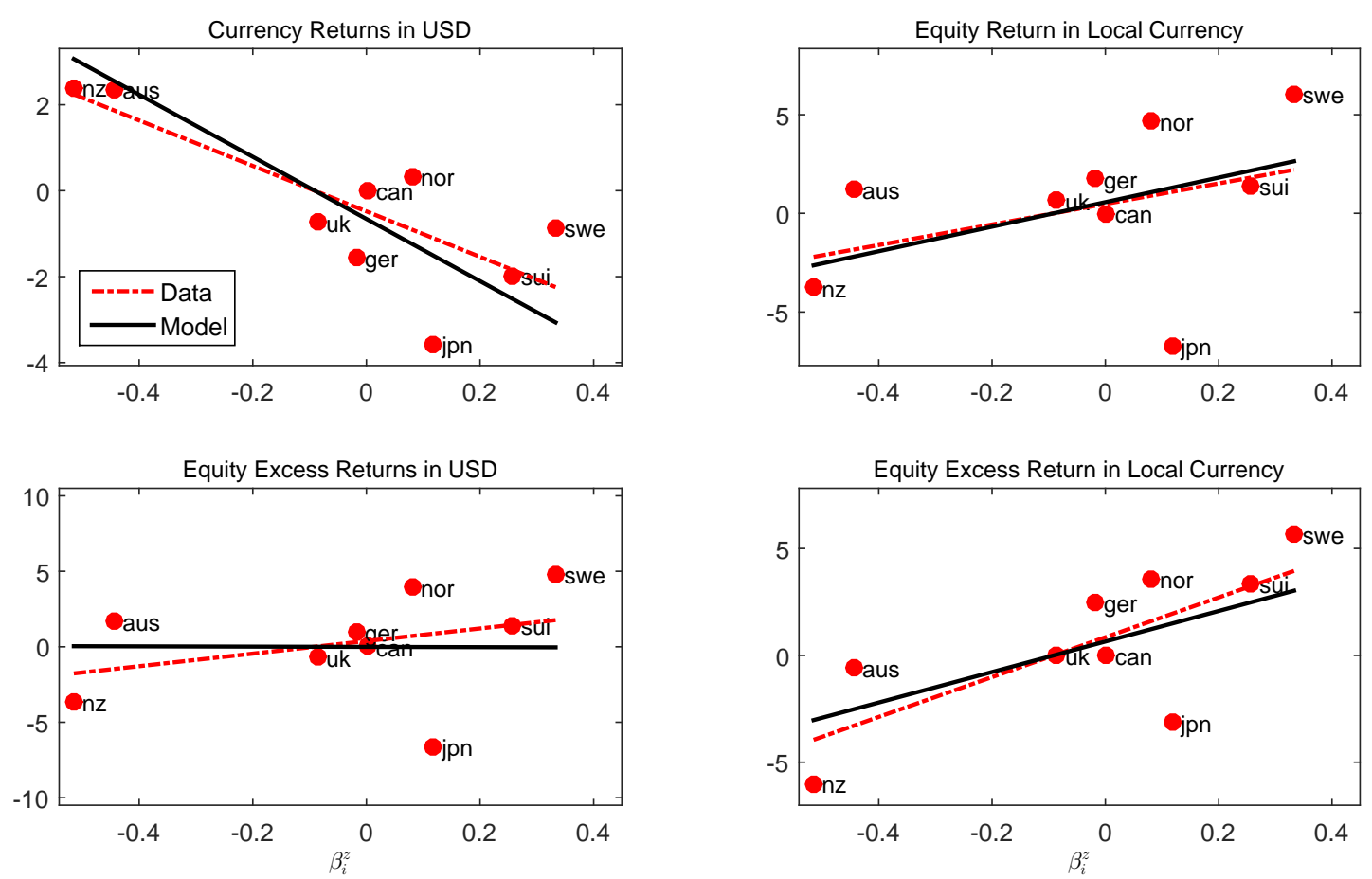

FIG. 5 - Equity and FX Excess Returns. In each panel, the horizontal axis refers to the estimated exposure coefficient $\beta_{i}^{z}$. For each country in our data set, we use the estimates provided in Table 1. The top-left panel links exposure to global long-run risk to average currency returns expressed in USD. The top-right (bottom-right) panel refers to average equity (excess) returns in each country. The bottom-left panel focuses on average excess returns from the perspective of a US-based investor. In each panel, the dots correspond to the actual data, the dashed line provides a linear fit of the data, and the thick line represents the model's prediction. The model is calibrated as in Table 2 and it features heterogenous exposure to global long-run growth shocks. All entries have been cross-sectionally demeaned in order to show deviations from the median country. The equity excess return in local units is defined as $r_{d, t}^{e x, i}=\lambda r_{c, t}^{e x, i}+\epsilon_{t}^{i}, i \in\{1,2, \ldots, N\}$, where $\lambda=6, r_{c, t}^{e x, i}$ is the excess return on the consumption claim, and $\epsilon_{t}^{i} \sim_{i . i . d .} N\left(0,0.15^{2}\right)$ captures dividend-specific shocks.

(bottom-left panel). Consistent with our risk-sharing mechanism, the exchange rate of countries with high exposure to global growth news represents a powerful hedge against equity risk.

The top left panel of Figure 6 documents that average risk-free rates are decreasing in the degree of exposure to global long-run risk, consistent with the precautionary saving channel discussed in the previous section. As in our model, countries typically featured in the long legs of carry-trade strategies (e.g., Australia and New Zealand) feature both low exposure to global risk and a large average risk-free rate. In contrast, 

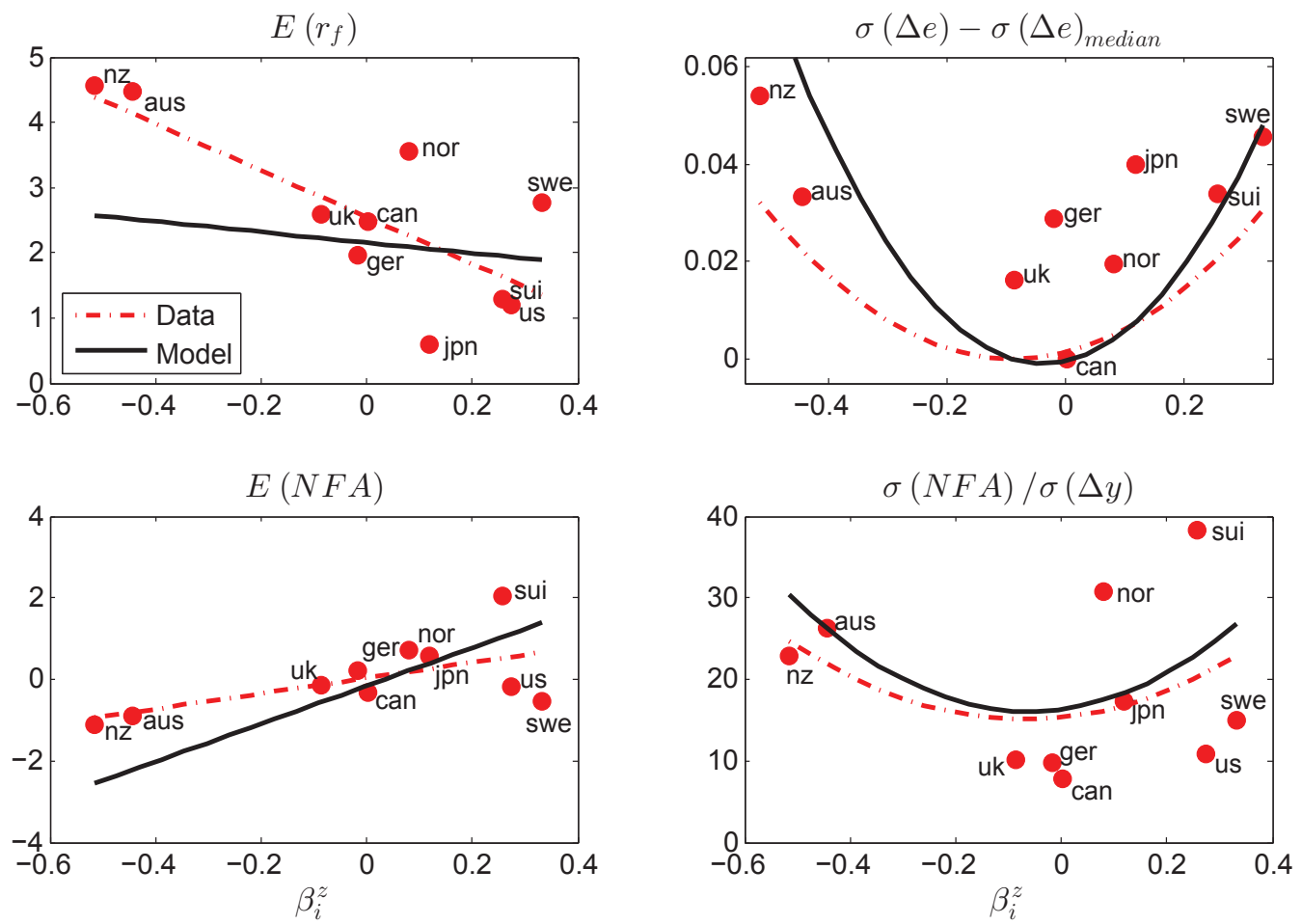

FIG. 6 - Cross-Sectional Patterns. In each panel, the horizontal axis refers to the estimated exposure coefficient $\beta_{i}^{z}$. For each country in our data set, we use the estimates provided in Table 1. The top-left panel links exposure to global long-run risk to the average risk-free rate in the cross section of countries. The top-right panel refers to the volatility of the growth rate of the real exchange rate of each country against the US dollar. Volatilities are expressed in terms of deviation from the median country. The bottom-left (right) panel focuses on the average level (volatility) of the net foreign assets to output ratio. In each panel, the dots correspond to the actual data, the dashed line provides a linear-quadratic fit of the data, and the thick line represents the model's prediction. The model is calibrated as in Table 2 and it features heterogenous exposure to global long-run growth shocks.

the set of countries commonly used as the funding currency (e.g., Switzerland) has a large $\beta$ and a low average interest rate.

By no arbitrage, the model suggests that the volatility of real exchange rates' fluctuations is a function of the spread of the $\beta$ 's across countries, i.e., countries with an exposure close to the median beta should have smooth exchange rates, whereas countries with extreme betas should have highly volatile currencies (the volatility smile). The top right panel of Figure 6 shows that this prediction finds strong support in the data, as the volatilities of the growth rate of the real exchange rate (vis-à-vis the US dollar) are well approximated by a concave quadratic function of the exposure 
coefficient.

Our risk sharing-based model predicts that countries with low exposure to global risk provide insurance to countries with high exposure to global risk in international capital markets. The bottom left panel of Figure 6 documents that our model's prediction lines up with the data, as countries like Australia and New Zealand (which have the lowest $\beta$ 's) have negative average net foreign asset positions and countries like the US, Switzerland, and Sweden (which have the largest $\beta$ 's) have positive average net foreign asset positions.

Additionally, the model predicts that countries with extreme $\beta$ 's should experience a larger extent of fluctuation in their net foreign asset positions, as they engage in a substantial amount of trading of securities to provide and receive insurance against their exposure to global risk (the reallocation channel). In contrast, countries with $\beta$ 's close to the median should have relatively smoother net foreign assets positions. As shown in the bottom right panel of Figure 6, this prediction is confirmed in the data.

We further explore the mechanism of the model by analyzing the response of foreign assets to a global long-run shock at a country level in our cross-section. For each country, we regress the time-series of the net foreign asset position on the level of the global long-run risk:

$$
\frac{N F A_{i, t}}{G D P_{i, t}}=\alpha_{i}^{N F A}+\lambda_{i}^{N F A} \cdot z_{g l o b a l, t}+\xi_{i, t} .
$$

According to our model, countries that have low exposure to global long-run risk (i.e. low $\beta$ countries) should experience an outflow (inflow) of resources at the occurrence of a negative (positive) global long-run shock. Equivalently, the $\lambda^{N F A}$ coefficient should be positive for countries with low $\beta$ and negative for countries with high $\beta$. We test this negative link in our cross-section of $\beta$-sorted countries by jointly estimating the 


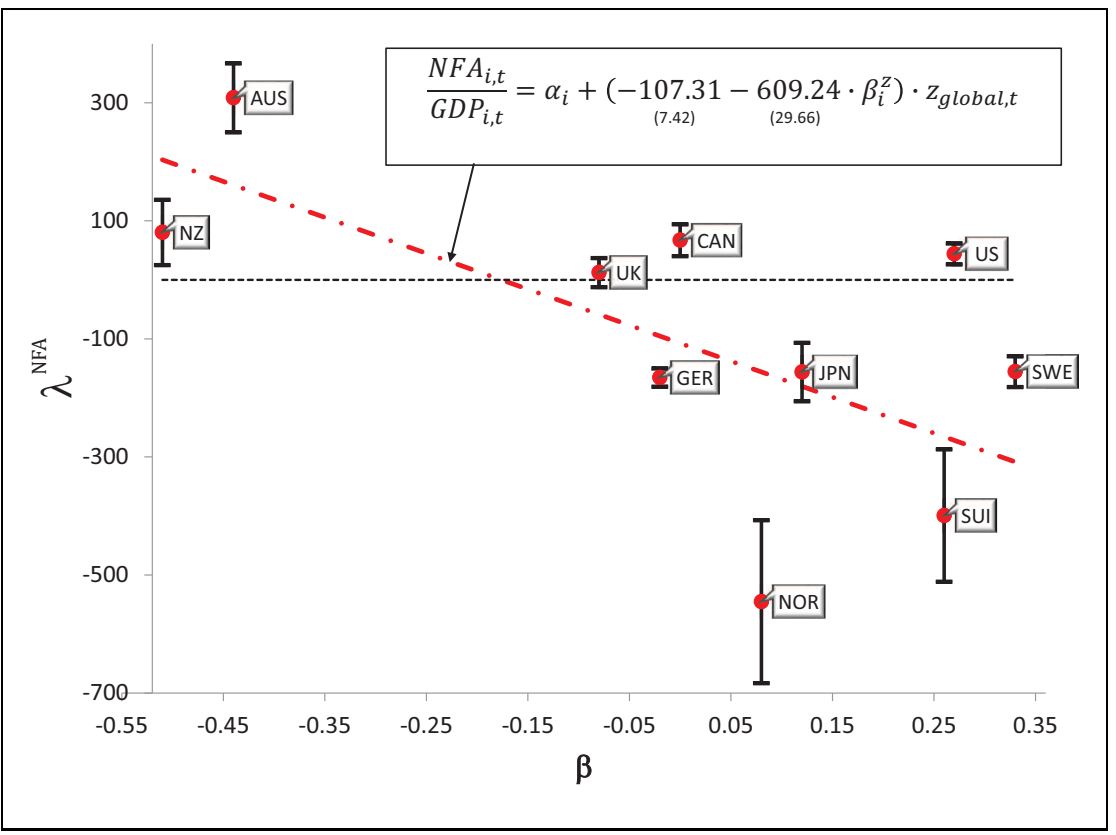

FIG. 7 - Each dot represents the estimated sensitivity of the net foreign assets over GDP of a country with respect to global long-run risk (see equation (20), coefficient $\lambda_{i}^{N F A}$ ). For each dot, the vertical line represents the $90 \%$ confidence interval associated to the estimated coefficient. The dashed line corresponds to the point estimate of the line $\vartheta_{0}^{N F A}+\vartheta_{1}^{N F A} \cdot \beta_{i}^{z}$ in equation (21). The estimated $\beta$ 's are reported in Table 1. Standard errors are adjusted for heteroscedasticity.

following system of equations via GMM:

$$
\frac{N F A_{i, t}}{G D P_{i, t}}=\alpha_{i}^{N F A}+\left(\vartheta_{0}^{N F A}+\vartheta_{1}^{N F A} \cdot \beta_{i}^{z}\right) \cdot z_{g l o b a l, t}+\xi_{i, t} \quad i=1,2, \ldots, 10
$$

Under the null hypothesis of the model, the estimated $\vartheta_{1}^{N F A}$ in equation (21) should be negative.

We illustrate our results in Figure 7. Countries with low $\beta$, such as Australia and New Zealand, have positive estimated coefficients $\lambda^{N F A}$ in equation (20), whereas countries with high $\beta$, such as Switzerland and Sweden, have negative estimated $\lambda^{N F A}$ coefficients. For the countries with the most extreme exposure to global shocks, we can typically reject the null hypothesis that their estimated $\lambda^{N F A}$ coefficient is equal to zero. Furthermore, the negative cross-sectional link between $\beta$ and $\lambda^{N F A}$ predicted by our model cannot be rejected in the data. 


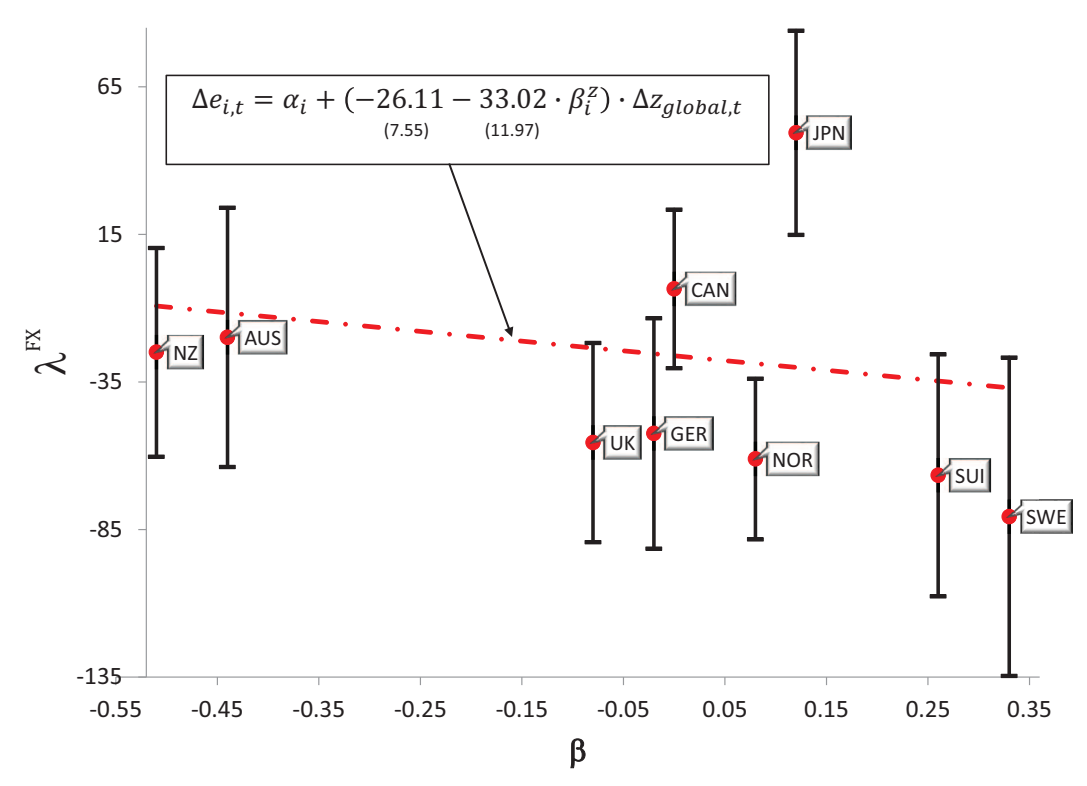

FIG. 8 - Each dot represents the estimated sensitivity of the growth rate of the exchange rate of a country's currency relative to the US Dollar with respect to a global long-run shock (see equation (22), coefficient $\lambda_{i}^{F X}$ ). For each dot, the vertical line represents the $90 \%$ confidence interval associated to the estimated coefficient. The dashed line corresponds to the point estimate of the line $\vartheta_{0}^{F X}+\vartheta_{1}^{F X} \cdot \beta_{i}^{z}$ in equation (23). The estimated $\beta$ 's are reported in Table 1. Standard errors are adjusted for heteroscedasticity.

We perform a similar analysis to study the response of each country's exchange rate to a global long-run shock. In particular, for each country $i$ we estimate the coefficients $\lambda_{i}^{F X}$ in

$$
\Delta e_{i, t}=\alpha_{i}^{F X}+\lambda_{i}^{F X} \cdot \Delta z_{g l o b a l, t}+\xi_{i, t}
$$

and then estimate the slope coefficient $\vartheta_{1}^{F X}$ in the following system of equations:

$$
\Delta e_{i, t}=\alpha_{i}^{F X}+\left(\vartheta_{0}^{F X}+\vartheta_{1}^{F X} \cdot \beta_{i}^{z}\right) \cdot \Delta z_{g l o b a l, t}+\xi_{i, t} \quad i=1,2, \ldots, 10 .
$$

We depict the results of this part of the analysis in Figure 8. Our model predicts that the currencies of countries with high exposure to global growth news (high $\beta$ ) experience stronger appreciations in response to negative global growth shocks. This is equivalent to a negative $\vartheta_{1}^{F X}$. In our cross-section, the estimate of this coefficient is 
negative and statistically significant, consistent with the model. ${ }^{5}$

We conclude this part of the analysis, by checking the robustness of our results to controlling for local growth news shocks and excluding specific countries. To streamline the presentation of the results, in Table 4 we focus on portfolios constructed according to countries' $\beta$ 's, as opposed to focusing on each country separately.

Specifically, we construct three portfolios based on the results of our analysis in Ta-

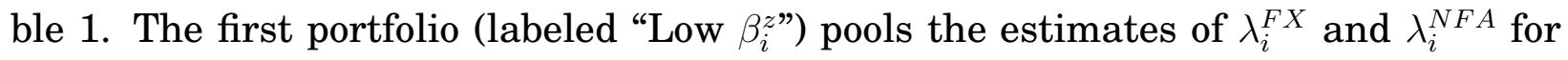
all the countries with negative and statistically different from zero $\beta$ 's (i.e. Australia and New Zealand). The second portfolio (labeled "Medium $\beta_{i}^{z ")}$ refers to the countries whose $\beta$ 's are not statistically different from zero (i.e. UK, Germany, Canada, Norway, and Japan). The third portfolio (labeled "High $\beta_{i}^{z "}$ ) consists of the countries with positive and statistically different from zero $\beta$ 's (i.e. US, Switzerland, and Sweden).

Columns [1] and [5] of Table 4 are the portfolio counterparts of the country-level estimated coefficients depicted in Figure 7 and Figure 8. Columns [2], [6], and [7] document that our results are robust to the exclusion of Japan and United States from portfolios 2 and 3, respectively.

In columns [3] and [4], we augment the specification in equation (22) by including the following two additional regressors: (i) the local long-run news for country $i$, and (ii) the local long-run news for the US, since the US is our base-country. Our results are robust to the inclusion of these additional control variables. In columns [8], [9], and [10], we perform a similar exercise by including the local long-run risk component as an additional variable in equation (20). The results are virtually unchanged relative

\footnotetext{
${ }^{5}$ Japan is the only notable outlier in Figure 8. This is due mostly to the strong depreciation of the Japanese Yen during the first part of the 1990's (see Obstfeld 2010 for a detailed account). This period also coincides with the time in which the Japanese Yen was less than prominently featured as the funding currency of carry trade strategies. We document in the Appendix that for the more recent 2007-2008 Great Recession, both the exchange rate and the NFA behaved exactly as predicted by the model (see Figure D3a and Figure D3b in the Appendix.)
} 
to columns [5], [6], and [7].

Overall, we regard the results presented in this section as strongly supporting our multicountry recursive risk-sharing mechanism. Our empirical findings confirm that the degree of heterogeneity in the exposure to global risk is well aligned with a number of quantities of interest in international financial markets. Furthermore, our general-equilibrium approach enables us to relate the no arbitrage-based hypothesis of Lustig et al. (2011) and Lustig et al. (2014) to macroeconomic fundamentals, such as international consumption dynamics.

\section{Concluding Remarks}

In this paper, we provide novel empirical evidence about cross-country heterogeneity in exposure to global long-run growth news. In particular, we show that heterogenous exposure to global long-run output growth risk simultaneously accounts for many currency risk-factor structures that have been proposed in the literature. We then develop a frictionless general-equilibrium model featuring long-run growth news shocks, and multiple countries with recursive preferences and produce an array of important economic implications that can be empirically assessed. We find a good alignment between our model and the data.

Future developments should focus on extending this setting to international real business cycle models in order to study the role of international investment flows and international frictions for the cross section of currency risk premia. The investigation of the roles of trading frictions, portfolio composition, and market incompleteness are other promising directions for future research. 
TABLE 4: Conditional Analysis

\begin{tabular}{|c|c|c|c|c|c|c|c|c|c|c|}
\hline \multirow[b]{2}{*}{ Portfolio } & \multicolumn{4}{|c|}{ Exchange Rate } & \multicolumn{6}{|c|}{ Net Foreign Assets } \\
\hline & [1] & {$[2]$} & [3] & [4] & [5] & [6] & {$[7]$} & {$[8]$} & [9] & {$[10]$} \\
\hline$\overline{\text { Low } \beta_{i}^{z}}$ & $\begin{array}{l}-26.52 \\
(16.05)\end{array}$ & $\begin{array}{l}-26.52 \\
(16.05)\end{array}$ & $\begin{array}{l}-27.51 \\
(13.91)\end{array}$ & $\begin{array}{l}-27.51 \\
(13.91)\end{array}$ & $\begin{array}{l}384.03 \\
(55.67)\end{array}$ & $\begin{array}{l}384.03 \\
(55.67)\end{array}$ & $\begin{array}{l}384.03 \\
(55.67)\end{array}$ & $\begin{array}{c}437.92 \\
(129.36)\end{array}$ & $\begin{array}{c}437.92 \\
(129.36)\end{array}$ & $\begin{array}{c}437.92 \\
(129.36)\end{array}$ \\
\hline Medium $\beta_{i}^{z}$ & $\begin{array}{l}-23.85 \\
(6.08)\end{array}$ & $\begin{array}{c}-38.49 \\
(9.35)\end{array}$ & $\begin{array}{l}-27.31 \\
(12.06)\end{array}$ & $\begin{array}{l}-52.15 \\
(12.72)\end{array}$ & $\begin{array}{l}-46.44 \\
(2.95)\end{array}$ & $\begin{array}{l}384.03 \\
(55.67)\end{array}$ & $\begin{array}{c}-15.74 \\
(1.95)\end{array}$ & $\begin{array}{l}33.44 \\
(7.79)\end{array}$ & $\begin{array}{l}33.44 \\
(7.79)\end{array}$ & $\begin{array}{c}7.23 \\
(7.36)\end{array}$ \\
\hline High $\beta_{i}^{z}$ & $\begin{array}{c}-67.16 \\
(23.75) \\
\end{array}$ & $\begin{array}{c}-67.16 \\
(23.75) \\
\end{array}$ & $\begin{array}{r}-84.88 \\
(20.43) \\
\end{array}$ & $\begin{array}{l}-84.88 \\
(20.43) \\
\end{array}$ & $\begin{array}{c}-154.46 \\
(33.57) \\
\end{array}$ & $\begin{array}{c}-149.21 \\
(24.20) \\
\end{array}$ & $\begin{array}{c}-154.46 \\
(33.57) \\
\end{array}$ & $\begin{array}{c}-141.02 \\
(22.72) \\
\end{array}$ & $\begin{array}{c}-144.54 \\
(22.69) \\
\end{array}$ & $\begin{array}{r}-141.02 \\
(22.72) \\
\end{array}$ \\
\hline Include All & - & - & - & - & $\mathrm{Y}$ & $\mathrm{N}$ & $\mathrm{N}$ & $\mathrm{Y}$ & $\mathrm{N}$ & $\mathrm{N}$ \\
\hline Exclude JPN & $\mathrm{N}$ & $\mathrm{Y}$ & $\mathrm{N}$ & $\mathrm{Y}$ & $\mathrm{N}$ & $\mathrm{N}$ & $\mathrm{Y}$ & $\mathrm{N}$ & $\mathrm{N}$ & $\mathrm{Y}$ \\
\hline Exclude US & $\mathrm{Y}$ & $\mathrm{Y}$ & $\mathrm{Y}$ & $\mathrm{Y}$ & $\mathrm{N}$ & $\mathrm{Y}$ & $\mathrm{N}$ & $\mathrm{N}$ & $\mathrm{Y}$ & $\mathrm{N}$ \\
\hline Control local shocks & $\mathrm{N}$ & $\mathrm{N}$ & $\mathrm{Y}$ & $\mathrm{Y}$ & $\mathrm{N}$ & $\mathrm{N}$ & $\mathrm{N}$ & $\mathrm{Y}$ & $\mathrm{Y}$ & $\mathrm{Y}$ \\
\hline
\end{tabular}

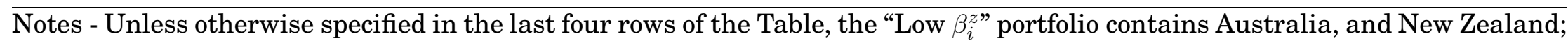

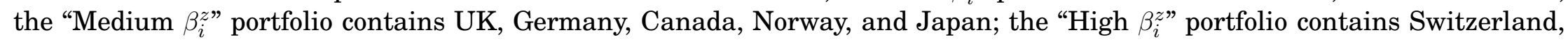
US, and Sweden. The United States are excluded from the analysis in columns [1]-[4], because the US Dollar is the base currency for this part of the analysis. The coefficients reported in columns [1] and [2] are obtained by pooling the coefficients $\lambda_{i}^{F X}$ in equation (22) for the countries of the corresponding portfolios. The coefficients in columns [3] and [4] repeat the same analysis, by augmenting equation (22) with the component of the domestic long-run shock that is orthogonal to the global long-run shock, i.e. $\Delta\left(z_{i, t}-\beta_{i}^{z} \cdot z_{\text {global }, t}\right)$, and the component of the US long-run shock that is orthogonal to the global long-run shock, i.e. $\Delta\left(z_{U S, t}-\beta_{U S}^{z} \cdot z_{\text {global }, t}\right)$. The coefficients reported in columns [5]-[7] are obtained by pooling the coefficients $\lambda_{i}^{N F A}$ in equation (20) for the countries of the corresponding portfolios. The coefficients in columns [8]-[10] repeat the same analysis, by augmenting equation (20) with the non-global component of the local long-run risk, i.e. $z_{i, t}-\beta_{i}^{z} \cdot z_{\text {global,t }}$, as an additional variable. For all configurations, the sample is 1987-2013. All standard errors are adjusted for heteroskedasticity. The average exposures to the global long-run risk $\left(\beta_{i}^{z}\right)$ are reported in Table D3 of the Appendix. 


\section{References}

Anderson, E. 2005. The dynamics of risk-sensitive allocations. Journal of Economic Theory 125(2):93-150.

Backus, D., and G. Smith. 1993. Consumption and real exchange rates in dynamic exchange economies with nontraded goods. Journal of International Economics 35: $297-316$.

Backus, D. K., F. Gavazzoni, C. Telmer, and S. E. Zin. July 2010. Monetary policy and the uncovered interest parity puzzle. (16218). Working Paper, NBER.

Bansal, R., and I. Shaliastovich. 2013. A long-run risks explanation of predictability puzzles in bond and currency markets. Review of Financial Studies 26(1):1-33.

Bansal, R., and A. Yaron. 2004. Risks for the long run: A potential resolution of asset pricing puzzles. Journal of Finance 59:1481-1509.

Bansal, R., D. Kiku, and A. Yaron. 2010. Risks for the long run: Estimation and inference. Working Paper.

Barro, R. 2006. Rare disasters and asset markets in the twentieth century. Quarterly Journal of Economics 121:823-866.

Brandt, W., J. Cochrane, and P. Santa-Clara. 2006. International risk sharing is better than you think, or exchange rates are too smooth. Journal of Monetary Economics 53(4):671-698.

Caballero, R. J., E. Farhi, and P.-O. Gourinchas. 2008. An equilibrium model of "global imbalances" and low interest rates. American Economic Review 98(1):358-93. 
Colacito, R. 2008. Six anomalies looking for a model. a consumption based explanation of international finance puzzles. Working Paper, Department of Finance, University of North Carolina, Chapel Hill NC.

Colacito, R., and M. Croce. 2013. International asset pricing with recursive preferences. Journal of Finance 68(6):2651-2686.

Colacito, R., and M. M. Croce. 2011. Risks for the long run and the real exchange rate. Journal of Political Economy 119(1):153-182.

Colacito, R., and M. M. Croce. 2012. Recursive allocations and wealth distribution with multiple goods. Working paper.

Della Corte, P., S. J. Riddiough, and L. Sarno. 2013. Currency premia and global imbalances. Working paper.

Epstein, L. G., and S. E. Zin. July 1989. Substitution, risk aversion, and the temporal behavior of consumption and asset returns: A theoretical framework. Econometrica 57(4):937-69.

Farhi, E., and X. Gabaix. 2008. Rare disasters and exchange rates. Working Paper, Harvard and NYU.

Farhi, E., and I. Werning. 2014. Dilemma not trilemma? Capital controls and exchange rates with volatile capital flows. IMF Economic Review 62(4):569-605.

Farhi, E., S. Fraiberger, X. Gabaix, R. Ranciere, and A. Verdelhan. 2015. Crash risk in currency markets. Working Paper, Harvard and NYU.

Froot, K. A., and J. C. Stein. 1991. Exchange rates and foreign direct investment: An imperfect capital markets approach. The Quarterly Journal of Economics 106(4): 1191-1217. 
Gabaix, X. 2012. Variable rare disasters: An exactly solved framework for ten puzzles in macro-finance. Quarterly Journal of Economics 127(2):645-700.

Gabaix, X., and M. Maggiori. 2015. International liquidity and exchange rate dynamics. Quarterly Journal of Economics, forthcoming.

Gourinchas, P.-O., and H. Rey. 2007. International financial adjustment. Journal of Political Economy 115(4):665-703.

Gourinchas, P.-O., and H. Rey. 2013. External adjustment, global imbalances and valuation effects. Handbook of International Economics 4.

Gourio, F. 2012. Disaster risk and business cycles. American Economic Review 102: $2734-2766$.

Gourio, F., M. Siemer, and A. Verdelhan. 2014. Uncertainty betas and international capital flows. MIT Working Paper.

Hassan, T. 2013. Country size, currency unions, and international asset returns. The Journal of Finance 68(6):2269-2308.

Hassan, T., and R. Mano. 2014. Forward and spot exchange rates in a multi-currency world. IMF and University of Chicago Working Paper.

Heyerdahl-Larsen, C. 2015. Asset Prices and Real Exchange Rates with Deep Habits. Review of Financial Studies.

Lane, P. R., and G. M. Milesi-Ferretti. 2007. The external wealth of nations mark ii: Revised and extended estimates of foreign assets and liabilities, 19702004. Journal of International Economics 73:223-250.

Lewis, K. 2011. Global asset pricing. Annual Reviews of Financial Economics. 
Lustig, H., and A. Verdelhan. 2007. The cross section of foreign currency risk premia and consumption growth risk. American Economic Review 97:89-117.

Lustig, H., N. Roussanov, and A. Verdelhan. 2011. Common risk factors in currency markets. Review of Financial Studies 24(11):3731-3777.

Lustig, H., N. Roussanov, and A. Verdelhan. 2014. Counter-cyclical currency risk premia. Journal of Financial Economics 111(3):527-553.

Maggiori, M. 2011. Financial intermediation, international risk sharing, and reserve currencies. Working paper.

Obstfeld, M. Time of troubles: The yen and Japan's economy, 1985-2008. In Hamada, K., A. Kashyap, and D. Weinstein, editors, Japan's Bubble, Deflation, and Long-term Stagnation chapter 3. MIT Press 2010.

Obstfeld, M., and K. Rogoff. 1995. Exchange rate dynamics redux. The Journal of Political Economy 103(3):624-660.

Rabitsch, K., S. Stepanchuk, and V. Tsyrennikov. 2015. International portfolios: A comparison of solution methods. Working Paper, Cornell University.

Ready, R., N. Roussanov, and C. Ward. 2012. Commodity Trade and the Carry Trade: A Tale of Two Countries. Working Paper, the Wharton School.

Stathopoulos, A. 2012. Asset prices and risk sharing in open economies. Working Paper, University of Washington.

Verdelhan, A. 2010. A habit-based explanation of the exchange rate risk premium. The Journal of Finance 65(1):123-145.

Verdelhan, A. 2015. The share of systematic risk in bilateral exchange rates. Working Paper, MIT. 
Weil, P. January 1989. The equity premium puzzle and the riskfree rate puzzle. Journal of Monetary Economics 24(3):401-422.

Zviadadze, I. 2013. Term-structure of consumption risk premia in the cross-section of currency returns. Working Paper Stockholm School of Economics. 


\section{Appendix}

\section{A Derivations for the Simple Economy.}

In this section, we are going to denote $\vartheta=\frac{1}{1-\gamma}$, and $\widetilde{\beta}_{i}=\left(1+\beta_{i}\right)$. Furthermore, we are going to provide formulas for the more general case in which $\operatorname{corr}\left(\varepsilon_{i, t+1}^{\sigma}, \varepsilon_{j, t+1}^{\sigma}\right)=\bar{\rho}^{\sigma} \in$ $[-1,1]$.

Lemma 1 (Equilibrium Utility). The equilibrium utility takes the form:

$$
V_{i, t}=U_{i, t}-\log C_{i, t}=A_{i}+B z_{i, t}+D_{i} \sigma_{i, t}
$$

where

$$
A_{i}=\frac{\delta}{1-\delta}\left[\mu_{c}+D_{i}\left(1-\rho_{\sigma}\right) \bar{\sigma}+\frac{D_{i}^{2}}{2 \vartheta} \sigma_{\sigma}\right], \quad B=\frac{\delta}{1-\delta \rho_{z}}, \quad D_{i}=\frac{\delta}{1-\delta \rho_{\sigma}}\left[\frac{1}{2 \vartheta}+\frac{B^{2} \varphi_{e}^{2}}{2 \vartheta}\left(1+\widetilde{\beta}_{i}^{2}\right)\right] .
$$

Proof of Lemma 1. We shall solve for $V_{i, t}=U_{i, t}-\log C_{i, t}$ :

$$
\begin{aligned}
V_{i, t} & =\delta \vartheta \log \left(E_{t}\left[\exp \left\{\frac{U_{i, t+1}-\log \left(C_{i, t+1}\right)+\Delta c_{i, t+1}}{\vartheta}\right\}\right]\right) \\
& =\delta \vartheta \log \left(E_{t}\left[\exp \left\{\frac{V_{i, t+1}+\mu_{c}+z_{i, t}+\sqrt{\sigma_{i, t}} \varepsilon_{i, t+1}^{c}}{\vartheta}\right\}\right]\right) .
\end{aligned}
$$

Guess that the solution is of the type $V_{i, t}=A_{i}+B_{i} z_{i, t}+D_{i} \sigma_{i, t}$. For compactness, we 
suppress the $i$ subscripts in the remainder of this derivation. Then:

$$
\begin{aligned}
V_{t}= & \delta \vartheta \log \left(E_{t}\left[\exp \left\{\frac{A+B x_{t+1}+D \sigma_{t+1}+\mu_{c}+z_{i, t}+\sqrt{\sigma_{i, t}} \varepsilon_{i, t+1}^{c}}{\vartheta}\right\}\right]\right) \\
= & \delta A+\delta \mu_{c}+\frac{\delta}{2 \vartheta} \sigma_{t}+\delta \vartheta \log \left(E _ { t } \left[\exp \left\{\frac{B}{\vartheta}\left(\rho_{z} z_{t}+\varphi_{e} \sqrt{\sigma_{t}}\left(\varepsilon_{t+1}^{x}+\beta \varepsilon_{t+1}^{g}\right)+\frac{D}{\vartheta}\left[\left(1-\rho_{\sigma}\right) \bar{\sigma}+\rho_{\sigma} \sigma_{t}+\sqrt{\sigma_{\sigma}} \varepsilon_{t+1}^{\sigma}\right\}\right]\right)\right.\right. \\
= & \delta\left[A+D\left(1-\rho_{\sigma}\right) \bar{\sigma}+\mu_{c}\right]+\delta\left[1+B \rho_{z}\right] z_{t}+\delta\left[\frac{1}{2 \vartheta}+D \rho_{\sigma}\right] \sigma_{t}+ \\
& \delta \vartheta \log \left(E_{t}\left[\exp \left\{\frac{B \varphi_{e}}{\vartheta} \sqrt{\sigma_{t}} \varepsilon_{t+1}^{x}+\frac{B \varphi_{e}}{\vartheta} \beta \sqrt{\sigma_{t}} \varepsilon_{t+1}^{g}+\frac{D}{\vartheta} \sqrt{\sigma_{\sigma}} \varepsilon_{t+1}^{\sigma}\right\}\right]\right) \\
= & \left.\delta\left[A+\mu_{c}+D\left(1-\rho_{\sigma}\right) \bar{\sigma}+\frac{D^{2}}{2 \vartheta} \sigma_{\sigma}\right]+\delta\left[1+B \rho_{z}\right] z_{t}+\delta\left[\frac{1}{2 \vartheta}+D \rho_{\sigma}\right]+\frac{B^{2} \varphi_{e}^{2}}{2 \vartheta}\left(1+\beta^{2}\right)\right] \sigma_{t}
\end{aligned}
$$

Matching coefficients concludes the proof.

Lemma 2 (Equilibrium SDF). The equilibrium SDF is:

$$
m_{t+1}=\log \delta-\Delta c_{t+1}+\frac{\tilde{V}_{t+1}}{\vartheta}-\frac{1}{\vartheta} E_{t}\left[\tilde{V}_{t+1}\right]-\frac{1}{2 \vartheta^{2}} \operatorname{Var}_{t}\left[\tilde{V}_{t+1}\right]
$$

where $\tilde{V}_{t}=V_{t}+\Delta c_{t}$, and $\tilde{V}_{t}$ is normally distributed.

Proof of Lemma 2. The logarithm of the SDF is

$$
\begin{aligned}
m_{t+1} & =\log \delta-\Delta c_{t+1}+\frac{1}{\vartheta} U_{t+1}-\log \left(E_{t}\left[\exp \left\{\frac{U_{t+1}}{\vartheta}\right\}\right]\right) \\
& =\log \delta-\Delta c_{t+1}+\frac{V_{t+1}+\Delta c_{t+1}}{\vartheta}-\log \left(E_{t}\left[\exp \left\{\frac{V_{t+1}+\Delta c_{t+1}}{\vartheta}\right\}\right]\right) \\
& =\log \delta-\Delta c_{t+1}+\frac{V_{t+1}+\Delta c_{t+1}}{\vartheta}-\log \left(E_{t}\left[\exp \left\{\frac{V_{t+1}+\Delta c_{t+1}}{\vartheta}\right\}\right]\right) .
\end{aligned}
$$

Denoting $\tilde{V}_{t}=V_{t}+\Delta c_{t}$, and using the properties of the log-normal distribution conclude the proof.

Lemma 3 (Conditional moments of the Utility). The conditional mean and variance 
of $\widetilde{V}_{i, t+1}$ are

$$
\begin{aligned}
E_{t}\left[\tilde{V}_{i, t+1}\right] & =\left[A_{i}+\mu_{c}+D_{i} \bar{\sigma}\left(1-\rho_{\sigma}\right)\right]+\left(B \rho_{z}+1\right) z_{t}+D_{i} \rho_{\sigma} \sigma_{i, t}, \\
\operatorname{Var}_{t}\left[\tilde{V}_{i, t+1}\right] & =\sigma_{i, t}\left(1+B^{2} \varphi_{e}^{2}\right)+B^{2} \varphi_{e}^{2} \beta^{2} \sigma_{i, t}+D_{i}^{2} \sigma_{\sigma},
\end{aligned}
$$

while its conditional covariance with consumption is equal to

$$
\operatorname{Cov}_{t}\left(\Delta c_{i, t+1}, \tilde{V}_{i, t+1}\right)=\sigma_{i, t}
$$

Proof of Lemma 3. To save on notation, we shall suppress the subscripts "i" in the remainder of this proof. Using the properties of the normal distribution, it follows immediately that the conditional mean is

$$
\begin{aligned}
E_{t}\left[\tilde{V}_{t+1}\right] & =E_{t}\left[A+B x_{t+1}+D \sigma_{t+1}+\mu_{c}+z_{t}+\sqrt{\sigma_{t}} \varepsilon_{t+1}^{c}\right] \\
& =A+\mu_{c}+E_{t}\left[B \rho_{z} z_{t}+B \varphi_{e} \sqrt{\sigma_{t}}\left(\varepsilon_{t+1}^{z}+\beta \varepsilon_{g l o b a l, t+1}\right)+z_{t}\right] \\
& =\left(A+\mu_{c}+D \bar{\sigma}\left(1-\rho_{\sigma}\right)\right)+\left(B \rho_{z}+1\right) z_{t}+D \rho_{\sigma} \sigma_{t}
\end{aligned}
$$

and that the conditional variance is

$$
\begin{aligned}
\operatorname{Var}_{t}\left[\tilde{V}_{t+1}\right] & =\operatorname{Var}_{t}\left[\sqrt{\sigma_{t}} \varepsilon_{t+1}^{c}+B \varphi_{e} \sqrt{\sigma_{t}}\left(\varepsilon_{t+1}^{x}+\beta \varepsilon_{g l o b a l, t+1}\right)+D \sqrt{\sigma_{\sigma}} \varepsilon_{t+1}^{\sigma}\right] \\
& =\sigma_{t}+B^{2} \varphi_{e}^{2}\left(1+\beta^{2}\right) \sigma_{t}+D^{2} \sigma_{\sigma} \\
& =\sigma_{t}\left(1+B^{2} \varphi_{e}^{2}\right)+B^{2} \varphi_{e}^{2} \beta^{2} \sigma_{t}+D^{2} \sigma_{\sigma} .
\end{aligned}
$$

Furthermore, it follows that the conditional covariance with consumption growth is equal to

$$
\operatorname{Cov}_{t}\left(\Delta c_{t+1}, \tilde{V}_{t+1}\right)=E_{t}\left[\left(\sqrt{\sigma_{t}} \varepsilon_{t+1}^{c}\right)\left(\sqrt{\sigma_{t}} \varepsilon_{t+1}^{c}+B \varphi_{e} \sqrt{\sigma_{t}}\left(\varepsilon_{t+1}^{x}+B \varepsilon_{\text {global }, t+1}\right)+D \sqrt{\sigma_{\sigma}} \varepsilon_{t+1}^{\sigma}\right)\right]=\sigma_{t}
$$


which concludes the proof.

Lemma 4 (Moments of the volatility process). For any two countries $i$ and $j$, the following unconditional moments attain

$$
\begin{aligned}
E\left[\sigma_{i, t}-\sigma_{j, t}\right] & =\bar{\sigma}_{i}-\bar{\sigma}_{j} \\
E\left[\widetilde{\beta}_{i} \sigma_{i, t}-\widetilde{\beta}_{j} \sigma_{j, t}\right] & =\widetilde{\beta}_{i} \bar{\sigma}_{i}-\widetilde{\beta}_{j} \bar{\sigma}_{j}, \\
\operatorname{Cov}\left[\left(\sigma_{i, t}-\sigma_{j, t}\right),\left(\widetilde{\beta}_{i} \sigma_{i, t}-\widetilde{\beta}_{j} \sigma_{j, t}\right)\right] & =\left(\widetilde{\beta}_{i}+\widetilde{\beta}_{j}\right) \cdot\left[\frac{\left(1-\bar{\rho}^{\sigma}\right) \sigma_{\sigma}}{1-\rho_{\sigma}^{2}}\right], \\
\operatorname{Var}\left[\sigma_{i, t}-\sigma_{j, t}\right] & =2 \cdot\left[\frac{\left(1-\bar{\rho}^{\sigma}\right) \sigma_{\sigma}}{1-\rho_{\sigma}^{2}}\right],
\end{aligned}
$$

Furthermore:

$$
E\left[\sqrt{\sigma_{i, t}} \sqrt{\sigma_{j, t}}\right]=\sqrt{\bar{\sigma}_{i}} \sqrt{\bar{\sigma}_{j}}+\frac{1}{4} \frac{\sigma_{\sigma}}{\sqrt{\bar{\sigma}_{i}} \sqrt{\bar{\sigma}_{j}}} \frac{\bar{\rho}^{\sigma}}{1-\rho_{\sigma}^{2}}
$$

up to a first order Taylor expansion.

Proof of Lemma 4. We omit the derivations of the two moments in (A1) and (A2), because straightforward. We shall proceed to the derivation of equation (A3). To save on notation, whenever there is no ambiguity, we shall suppress the subscripts "i". First, note that:

$$
\begin{aligned}
E\left[\sigma_{t}^{2}\right] & =E\left[\bar{\sigma}^{2}\left(1-\rho_{\sigma}\right)^{2}+\rho_{\sigma}^{2} \sigma_{t-1}^{2}+\sigma_{\sigma}\left(\varepsilon_{t}^{\sigma}\right)^{2}+2 \bar{\sigma}\left(1-\rho_{\sigma}\right) \rho_{\sigma} \sigma_{t-1}+2 \bar{\sigma}\left(1-\rho_{\sigma}\right) \sqrt{\sigma_{\sigma}} \varepsilon_{t}^{\sigma}+2 \rho_{\sigma} \sigma_{t-1} \sqrt{\sigma_{\sigma}} \varepsilon_{t}^{\sigma}\right] \\
& =\bar{\sigma}^{2}\left(1-\rho_{\sigma}\right)^{2}+\rho_{\sigma}^{2} E\left[\sigma_{t}^{2}\right]+\sigma_{\sigma}+2 \bar{\sigma}^{2}\left(1-\rho_{\sigma}\right) \rho_{\sigma} \\
& =\bar{\sigma}^{2} \frac{\left(1-\rho_{\sigma}^{2}-2 \rho_{\sigma}+2 \rho_{\sigma}-2 \rho_{\sigma}^{2}\right)}{1-\rho_{\sigma}^{2}}+\frac{\sigma_{\sigma}}{1-\rho_{\sigma}^{2}}=\bar{\sigma}^{2}+\frac{\sigma_{\sigma}}{1-\rho_{\sigma}^{2}}
\end{aligned}
$$

and that

$$
\begin{aligned}
E\left[\left(\sigma_{i, t}-\bar{\sigma}_{i}\right)\left(\sigma_{j, t}-\bar{\sigma}_{j}\right)\right] & =E\left[\left(\rho_{\sigma}\left(\sigma_{i, t-1}-\bar{\sigma}_{i}\right)+\sqrt{\sigma_{\sigma}} \varepsilon_{i, t}^{\sigma}\right)\left(\rho_{\sigma}\left(\sigma_{j, t-1}-\bar{\sigma}_{j}\right)+\sqrt{\sigma_{\sigma}} \varepsilon_{j, t}^{\sigma}\right)\right] \\
& =\rho_{\sigma}^{2} E\left[\left(\sigma_{i, t-1}-\bar{\sigma}_{i}\right)\left(\sigma_{j, t-1}-\bar{\sigma}_{j}\right)\right]+\sigma_{\sigma} \bar{\rho}^{\sigma}=\frac{\sigma_{\sigma} \bar{\rho}^{\sigma}}{1-\rho_{\sigma}^{2}}
\end{aligned}
$$


which allows us to obtain:

$$
\begin{aligned}
E\left[\sigma_{i, t} \sigma_{j, t}\right] & =E\left[\left(\sigma_{i, t}-\bar{\sigma}_{i}\right)\left(\sigma_{j, t}-\bar{\sigma}_{j}\right)\right]+E\left[\sigma_{i, t}\right] E\left[\sigma_{j, t}\right] \\
& =E\left[\left(\sigma_{i, t}-\bar{\sigma}_{i}\right)\left(\sigma_{j, t}-\bar{\sigma}_{j}\right)\right]+\bar{\sigma}_{i} \bar{\sigma}_{j}=\bar{\sigma}_{i} \bar{\sigma}_{j}+\frac{\sigma_{\sigma} \bar{\rho}^{\sigma}}{1-\rho_{\sigma}^{2}} .
\end{aligned}
$$

It then follows that:

$$
\begin{aligned}
\operatorname{Cov}\left[\left(\sigma_{i, t}-\sigma_{j, t}\right),\left(\widetilde{\beta}_{i} \sigma_{i, t}-\widetilde{\beta}_{j} \sigma_{j, t}\right)\right]= & E\left[\left(\sigma_{i, t}-\sigma_{j, t}\right)\left(\widetilde{\beta}_{i} \sigma_{i, t}-\widetilde{\beta}_{j} \sigma_{j, t}\right)\right]-E\left[\left(\sigma_{i, t}-\sigma_{j, t}\right)\right] \cdot E\left[\left(\widetilde{\beta}_{i} \sigma_{i, t}-\widetilde{\beta}_{j} \sigma_{j, t}\right)\right] \\
= & \widetilde{\beta}_{i} E\left[\sigma_{i, t}^{2}\right]-\widetilde{\beta}_{j} E\left[\sigma_{i, t}, \sigma_{j, t}\right]-\widetilde{\beta}_{i} E\left[\sigma_{i, t} \sigma_{j, t}\right]+\widetilde{\beta}_{j} E\left[\sigma_{j, t}^{2}\right]-\left(\bar{\sigma}_{i}-\bar{\sigma}_{j}\right) \cdot\left(\widetilde{\beta}_{i} \bar{\sigma}_{i}-\widetilde{\beta}_{j} \bar{\sigma}_{j}\right) \\
= & \widetilde{\beta}_{i} \bar{\sigma}_{i}^{2}+\widetilde{\beta}_{i} \frac{\sigma_{\sigma}}{1-\rho_{\sigma}^{2}}-\left(\widetilde{\beta}_{i}+\widetilde{\beta}_{j}\right)\left(\bar{\sigma}_{i} \bar{\sigma}_{j}+\bar{\rho}^{\sigma} \frac{\sigma_{\sigma}}{1-\rho_{\sigma}^{2}}\right)+\widetilde{\beta}_{j} \bar{\sigma}_{j}^{2}+\widetilde{\beta}_{j} \frac{\sigma_{\sigma}}{1-\rho_{\sigma}^{2}} \\
& -\left[\widetilde{\beta}_{i} \bar{\sigma}_{i}^{2}-\widetilde{\beta}_{j} \bar{\sigma}_{i} \bar{\sigma}_{j}-\widetilde{\beta}_{i} \bar{\sigma}_{i} \bar{\sigma}_{j}+\widetilde{\beta}_{j} \bar{\sigma}_{j}^{2}\right] \\
= & \left(\widetilde{\beta}_{i}+\widetilde{\beta}_{j}\right)\left(1-\bar{\rho}^{\sigma}\right) \frac{\sigma_{\sigma}}{1-\rho_{\sigma}^{2}},
\end{aligned}
$$

which concludes the derivation of equation (A3).

The derivation of equation (A4) is straightforward:

$$
\begin{aligned}
\operatorname{Var}\left[\sigma_{i, t}-\sigma_{j, t}\right] & =\operatorname{Var}\left[\sigma_{i, t}\right]+\operatorname{Var}\left[\sigma_{j, t}\right]-2 \operatorname{Cov}\left[\sigma_{i, t}, \sigma_{j, t}\right] \\
& =2 \cdot \frac{\sigma_{\sigma}}{1-\rho_{\sigma}^{2}}-2 \cdot \frac{\sigma_{\sigma}}{1-\rho_{\sigma}^{2}} \bar{\rho}^{\sigma}=2\left(1-\bar{\rho}^{\sigma}\right) \frac{\sigma_{\sigma}}{1-\rho_{\sigma}^{2}}
\end{aligned}
$$

In order to obtain equation (A5), we first need to find an approximate solution for $E\left[\sqrt{\sigma_{i, t}} \sqrt{\sigma_{j, t}}\right]$. Let us consider a first order Taylor expansion:

$$
\begin{aligned}
\sqrt{\sigma_{t}} & =\sqrt{\bar{\sigma}\left(1-\rho_{\sigma}\right)+\rho_{\sigma}\left(\sqrt{\sigma_{t-1}}\right)^{2}+\sqrt{\sigma_{\sigma}} \varepsilon_{t}^{\sigma}} \\
& =\sqrt{\bar{\sigma}\left(1-\rho_{\sigma}\right)+\rho_{\sigma} \bar{\sigma}}+\frac{1}{2} \frac{2 \rho_{\sigma} \sqrt{\bar{\sigma}}}{\sqrt{\bar{\sigma}}}\left(\sqrt{\sigma_{t-1}}-\sqrt{\bar{\sigma}}\right)+\frac{1}{2} \frac{\sqrt{\sigma_{\sigma}}}{\bar{\sigma}} \varepsilon_{\sigma, t} \\
& =\left(1-\rho_{\sigma}\right) \sqrt{\bar{\sigma}}+\rho_{\sigma} \sqrt{\sigma_{t-1}}+\frac{1}{2} \sqrt{\frac{\sigma_{\sigma}}{\bar{\sigma}}} \varepsilon_{t}^{\sigma},
\end{aligned}
$$


from which it follows immediately

$$
\begin{aligned}
E\left[\sqrt{\sigma_{i, t}} \sqrt{\sigma_{j, t}}\right]= & E\left[\left(1-\rho_{\sigma}\right)^{2}+\sqrt{\bar{\sigma}_{i}} \sqrt{\bar{\sigma}_{j}}+\rho_{\sigma}\left(1-\rho_{\sigma}\right) \sqrt{\bar{\sigma}_{j}} \sqrt{\sigma_{i, t-1}}+\frac{\left(1-\rho_{\sigma}\right) \sqrt{\sigma_{\sigma}}}{2} \varepsilon_{i, t}^{\sigma}\right. \\
& +\rho_{\sigma}\left(1-\rho_{\sigma}\right) \sqrt{\bar{\sigma}_{i}} \sqrt{\sigma_{j, t-1}}+\rho_{\sigma}^{2} \sqrt{\sigma_{i, t-1}} \sqrt{\sigma_{j, t-1}}+\frac{1}{2} \rho_{\sigma} \sqrt{\frac{\sigma_{\sigma}}{\bar{\sigma}_{i}}} \sqrt{\sigma_{j, t-1}} \varepsilon_{i, t}^{\sigma} \\
& \left.+\frac{1}{2}\left(1-\rho_{\sigma}\right) \sqrt{\sigma_{\sigma}} \varepsilon_{j, t}^{\sigma}+\frac{1}{2} \rho_{\sigma} \sqrt{\frac{\sigma_{\sigma}}{\bar{\sigma}_{j}}} \sqrt{\sigma_{i, t-1}} \varepsilon_{j, t}^{\sigma}+\frac{1}{4} \frac{\sigma_{\sigma}}{\sqrt{\bar{\sigma}_{i}} \sqrt{\bar{\sigma}_{j}}} \varepsilon_{i, t}^{\sigma} \varepsilon_{j, t}^{\sigma}\right] .
\end{aligned}
$$

Since all the shocks are mean-zero:

$$
\begin{aligned}
E\left[\sqrt{\sigma_{i, t}} \sqrt{\sigma_{j, t}}\right] & =\left(1-\rho_{\sigma}\right)^{2} \sqrt{\bar{\sigma}_{i}} \sqrt{\bar{\sigma}_{j}}+2 \rho_{\sigma}\left(1-\rho_{\sigma}\right) \sqrt{\overline{\sigma_{i}}} \sqrt{\overline{\sigma_{j}}}+\rho_{\sigma}^{2} E\left[\sqrt{\sigma_{i, t-1}} \sqrt{\sigma_{j, t-1}}\right]+\frac{1}{4} \frac{\sigma_{\sigma}}{\sqrt{\bar{\sigma}_{i}} \sqrt{\bar{\sigma}_{j}}} \bar{\rho}^{\sigma} \\
& =\sqrt{\overline{\sigma_{i}}} \sqrt{\bar{\sigma}_{j}}\left(1+\rho_{\sigma}^{2}-2 \rho_{\sigma}+2 \rho_{\sigma}-2 \rho_{\sigma}^{2}\right)+\rho_{\sigma}^{2} E\left[\sqrt{\sigma_{i, t-1}} \sqrt{\sigma_{j, t-1}}\right]+\frac{1}{4} \frac{\sigma_{\sigma}}{\sqrt{\bar{\sigma}_{i}} \sqrt{\bar{\sigma}_{j}} \bar{\rho}^{\sigma}} \\
& =\sqrt{\overline{\sigma_{i}}} \sqrt{\bar{\sigma}_{j}}+\frac{1}{4} \frac{\sigma_{\sigma}}{\sqrt{\bar{\sigma}_{i}} \sqrt{\bar{\sigma}_{j}}} \frac{\bar{\rho}^{\sigma}}{1-\rho_{\sigma}^{2}},
\end{aligned}
$$

which concludes the proof.

\section{A.1 Carry Trade}

In this section we describe the derivations of the cross-sectional currency risk premium. To save of notation, we are going to drop the superscripts $k$ for the base currency.

Lemma 5 (Currency Risk Premium). Let the currency of country $k$ be the base currency. The logarithm of the conditional currency risk premium on currency $i$ is:

$$
\begin{aligned}
\log E_{t}\left[R X_{t+1}^{i}\right]= & \left(1-\frac{1}{\vartheta}\right)^{2} \sqrt{\sigma_{k, t}}\left(\sqrt{\sigma_{k, t}}-\bar{\rho}^{c} \sqrt{\sigma_{i, t}}\right)+\frac{B^{2}}{\vartheta^{2}} \varphi_{e}^{2} \sigma_{k, t} \\
& +\frac{B^{2}}{\vartheta^{2}} \varphi_{e}^{2} \widetilde{\beta}_{k} \sqrt{\sigma_{k, t}}\left(\widetilde{\beta}_{k} \sqrt{\sigma_{k, t}}-\widetilde{\beta}_{i} \sqrt{\sigma_{i, t}}\right)+\frac{D_{k}}{\vartheta^{2}} \sigma_{\sigma}\left(D_{k}-\bar{\rho}^{\sigma} D_{i}\right)
\end{aligned}
$$

Proof of Lemma 5. The logarithm of the conditional currency risk premium on cur- 
rency $i$ is:

$$
\begin{aligned}
\log E_{t}\left[R X_{t+1}^{i}\right] & =\log E_{t} \exp \left\{\Delta e_{t+1}^{k, i}-r_{k, t}+r_{i, t}\right\} \\
& =\log E_{t} \exp \left\{m_{t+1}^{i}-m_{t+1}^{k}-\left(-E_{t}\left[m_{t+1}^{k}\right]-\frac{\operatorname{Var}_{t}\left[m_{t+1}^{k}\right]}{2}\right)+\left(-E_{t}\left[m_{t+1}^{i}\right]-\frac{\operatorname{Var}_{t}\left[m_{t+1}^{i}\right]}{2}\right)\right\} \\
& =\operatorname{Var}_{t}\left[m_{t+1}^{k}\right]-\operatorname{Covt}_{t}\left[m_{t+1}^{k}, m_{t+1}^{i}\right],
\end{aligned}
$$

where the last equality follows from the properties of the log-normal distribution. We start by calculating $\operatorname{Var}_{t}\left[m_{t+1}\right]$, where we are dropping the country subscript for convenience. First compute the conditional expectation

$$
E_{t}\left[m_{t+1}\right]=\log (\delta)-E_{t}\left[\Delta c_{t+1}\right]-\frac{1}{2} \operatorname{Var}_{t}\left[\widetilde{V}_{t+1}\right]
$$

which allows to write the excess stochastic discount factor as

$$
m_{t+1}-E_{t}\left[m_{t+1}\right]=-\left(1-\frac{1}{\vartheta}\right) \sqrt{\sigma_{t}} \varepsilon_{t+1}^{c}+\frac{B}{\vartheta} \varphi_{e} \sqrt{\sigma_{t}}\left(\varepsilon_{t+1}^{z}+\beta \varepsilon_{g l o b a l, t+1}\right)+\frac{D}{\vartheta} \sqrt{\sigma_{\sigma}} \varepsilon_{t+1}^{\sigma},
$$

and, finally:

$$
\operatorname{Var}_{t}\left[m_{t+1}\right]=\left(1-\frac{1}{\vartheta}\right)^{2} \sigma_{t}+\frac{B^{2}}{\vartheta^{2}} \varphi_{e}^{2}\left(1+\beta^{2}\right) \sigma_{t}+\frac{D^{2}}{\vartheta^{2}} \sigma_{\sigma}
$$

Now we calculate the conditional covariance:

$$
\begin{aligned}
\operatorname{Cov}_{t}\left[m_{i, t+1}, m_{j, t+1}\right] & =E_{t}\left[\left(m_{i, t+1}-E_{t}\left[m_{i, t+1}\right]\right) \cdot\left(m_{j, t+1}-E_{t}\left[m_{j, t+1}\right]\right)\right] \\
& =\left[\left(1-\frac{1}{\vartheta}\right)^{2} \bar{\rho}^{c}+\left(\frac{B}{\vartheta} \varphi_{e}\right)^{2} \widetilde{\beta}_{i} \widetilde{\beta}_{j}\right] \sqrt{\sigma_{i, t}} \sqrt{\sigma_{j, t}}+\frac{\sigma_{\sigma} D_{i} D_{j} \bar{\rho}^{\sigma}}{\vartheta^{2}} .
\end{aligned}
$$

The formula for $E_{t}\left[R X_{t+1}^{i}\right]$ reported in (A6) follows immediately.

Proof of Proposition. From Lemma 5, it follows that the spread between low exposure 
("L”) and high exposure ("H") countries:

$$
\begin{aligned}
\log E_{t}\left[R X_{t+1}^{L}\right]-\log E_{t}\left[R X_{t+1}^{H}\right]= & \left(1-\frac{1}{\vartheta}\right)^{2} \sqrt{\sigma_{k, t}}\left(\sqrt{\sigma_{H, t}}-\sqrt{\sigma_{L, t}}\right) \bar{\rho}^{c} \\
& +\frac{B^{2}}{\vartheta^{2}} \varphi_{e}^{2} \widetilde{\beta}_{k} \sqrt{\sigma_{k, t}}\left(\beta_{H} \sqrt{\sigma_{H, t}}-\beta_{L} \sqrt{\sigma_{L, t}}\right)+\frac{D}{\vartheta^{2}} \sigma_{\sigma}\left(D_{H}-D_{L}\right) \bar{\rho}^{\sigma} .
\end{aligned}
$$

Consider the unconditional expectation of the above formula:

$$
\begin{aligned}
& E\left[\log E_{t}\left[R X_{t+1}^{L}\right]-\log E_{t}\left[R X_{t+1}^{H}\right]\right]=E\left[H M L_{t}\right] \\
& =\frac{B^{2}}{\vartheta^{2}} \varphi_{e}^{2} \widetilde{\beta}_{k}\left(\beta_{H}-\beta_{L}\right) E\left[\sqrt{\sigma_{k, t}} \sqrt{\sigma_{i, t}}\right]+\frac{D_{k}}{\vartheta} \sigma_{\sigma}\left(D_{H}-D_{L}\right) \bar{\rho}^{\sigma} \\
& =\frac{B^{2}}{\vartheta^{2}} \varphi_{e}^{2} \widetilde{\beta}_{k}\left(\beta_{H}-\beta_{L}\right)\left(\sqrt{\overline{\sigma_{k}}} \sqrt{\overline{\sigma_{i}}}\right)+\frac{B^{2}}{\vartheta^{2}} \varphi_{e}^{2} \widetilde{\beta}_{k}\left(\beta_{H}-\beta_{L}\right) \frac{\bar{\rho}^{\sigma} \sigma_{\sigma}}{4 \sqrt{\bar{\sigma}_{k}} \sqrt{\bar{\sigma}_{i}}\left(1-\rho_{\sigma}^{2}\right)} \\
& +\frac{D_{k}}{\vartheta^{2}} \sigma_{\sigma}\left(D_{H}-D_{L}\right) \bar{\rho}^{\sigma} \text {. }
\end{aligned}
$$

If we assume that the correlation of the volatility shocks is equal to zero (i.e. $\bar{\rho}^{\sigma}=0$ ):

$$
E\left[H M L_{t}\right]=\frac{B^{2}}{\vartheta^{2}} \varphi_{e}^{2} \widetilde{\beta}_{k}\left(\beta_{H} \sqrt{\bar{\sigma}_{H}}-\beta_{L} \sqrt{\bar{\sigma}_{L}}\right) \sqrt{\bar{\sigma}_{k}},
$$

which concludes the derivations for the unconditional carry trade risk premium.

\section{A.2 Forward Premium Puzzle}

In this section, we first characterize the risk-free rates, then the expected exchange rates' growth rate, and finally the slope coefficient in the Uncovered Interest Rate Parity regression.

Lemma 6 (Risk-free rates). For any two countries $i$ and $j$, the difference of the risk-free rates is:

$$
r_{i, t}-r_{j, t}=\left(z_{i, t}-z_{j, t}\right)+\left(\frac{1}{\vartheta}-\frac{1}{2}\right)\left(\sigma_{i, t}-\sigma_{j, t}\right) .
$$


Proof of Lemma 6. The risk-free rate for a generic country $i$ is

$$
\begin{aligned}
r_{i, t} & =-\log E_{t} \exp \left\{m_{i, t+1}\right\} \\
& =-\log E_{t} \exp \left\{\log (\delta)-\Delta c_{i, t+1}+\frac{\widetilde{V}_{i, t+1}}{\vartheta}-\frac{E_{t}\left[\widetilde{V}_{i, t+1}\right]}{\vartheta}-\frac{\operatorname{Var}_{t}\left[\widetilde{V}_{i, t+1}\right]}{2 \vartheta^{2}}\right\}
\end{aligned}
$$

Using the properties of the log-normal distribution:

$$
\begin{aligned}
r_{i, t}= & -\log (\delta)+E_{t}\left[\Delta c_{i, t+1}\right]-\frac{1}{2} \operatorname{Var}_{t}\left[\Delta c_{i, t+1}\right]-\frac{E_{t}\left[\widetilde{V}_{i, t+1}\right]}{\vartheta}-\frac{\operatorname{Var}_{t}\left[\widetilde{V}_{i, t+1}\right]}{2 \vartheta^{2}}+\frac{E_{t}\left[\widetilde{V}_{i, t+1}\right]}{\vartheta} \\
& +\frac{\operatorname{Var}_{t}\left[\widetilde{V}_{i, t+1}\right]}{2 \vartheta^{2}}+\frac{\operatorname{Cov}_{t}\left[\Delta c_{i, t+1}, \widetilde{V}_{i, t+1}\right]}{\vartheta} \\
= & -\log (\delta)+\left(\mu_{c}+z_{i, t}\right)-\frac{\sigma_{i, t}}{2}+\frac{\sigma_{i, t}}{\vartheta},
\end{aligned}
$$

or, equivalently,

$$
r_{i, t}=\left[\mu_{c}-\log (\delta)\right]+z_{i, t}+\left(\frac{1}{\vartheta}-\frac{1}{2}\right) \sigma_{i, t}
$$

Equation (A11) implies that the unconditional expectation of the risk-free rate is

$$
E\left[r_{i, t}\right]=\left[\mu_{c}-\log (\delta)\right]+\left(\frac{1}{\vartheta}-\frac{1}{2}\right) \bar{\sigma}_{i}
$$

Taking the difference of equation (A11) for two countries $i$ and $j$ delivers equation (A9).

Lemma 7 (Exchange rates). The expected growth rate of the exchange rate between the currencies of countries $i$ and $j$ is:

$$
E_{t}\left[\Delta e_{t+1}^{i, j}\right]=\left(z_{i, t}-z_{j, t}\right)+\frac{\left[D_{i}^{2}-D_{j}^{2}\right]}{2 \vartheta^{2}} \sigma_{\sigma}+\frac{\left.\left[1+\left(B \varphi_{e}\right)^{2}\right)\right]}{2 \vartheta^{2}}\left(\sigma_{i, t}-\sigma_{j, t}\right)+\frac{\left(B \varphi_{e}\right)^{2}}{2 \vartheta^{2}}\left(\widetilde{\beta}_{i} \sigma_{i, t}-\widetilde{\beta}_{j} \sigma_{j, k}(\AA) 13\right)
$$

Proof of Lemma 7. Since markets are complete, the growth rate of the exchange rate 
between countries $i$ and $j$ is:

$$
\begin{aligned}
E_{t}\left[\Delta e_{t+1}^{i, j}\right] & =E_{t}\left[m_{j, t+1}-m_{i, t+1}\right]=\left(z_{i, t}-z_{j, t}\right)+\frac{1}{2 \vartheta^{2}}\left(\operatorname{Var}_{t}\left[\widetilde{V}_{i, t+1}\right]-\operatorname{Var}_{t}\left[\widetilde{V}_{j, t+1}\right]\right) \\
& =\left(z_{i, t}-z_{j, t}\right)+\frac{\left[D_{i}^{2}-D_{j}^{2}\right]}{2 \vartheta^{2}} \sigma_{\sigma}+\frac{\left.\left[1+\left(B \varphi_{e}\right)^{2}\right)\right]}{2 \vartheta^{2}}\left(\sigma_{i, t}-\sigma_{j, t}\right)+\frac{\left(B \varphi_{e}\right)^{2}}{2 \vartheta^{2}}\left(\widetilde{\beta}_{i} \sigma_{i, t}-\widetilde{\beta}_{j} \sigma_{j, t}\right),
\end{aligned}
$$

which concludes the proof.

Proof of Proposition 2. Using equations (A9) and (A13), the expected exchange rate can be written as

$$
\begin{aligned}
E_{t}\left[\Delta e_{t+1}^{i, j}\right]= & \underbrace{\frac{\left[D_{i}^{2}-D_{j}^{2}\right]}{2 \vartheta^{2}} \sigma_{\sigma}}_{\alpha_{F P P}}+\underbrace{1}_{\beta_{r, F P P}} \cdot \underbrace{\left[\left(z_{i, t}-z_{j, t}\right)+\left(\frac{1}{\vartheta}-\frac{1}{2}\right)\left(\sigma_{i, t}-\sigma_{j, t}\right)\right]}_{r_{i, t}-r_{j, t}} \\
& +\underbrace{\left[\frac{\left.1+\left(B \varphi_{e}\right)^{2}\right)}{2 \vartheta^{2}}-\left(\frac{1}{\vartheta}-\frac{1}{2}\right)\right]}_{\beta_{\sigma, F P P}}\left(\sigma_{i, t}-\sigma_{j, t}\right)+\underbrace{\frac{\left(B \varphi_{e}\right)^{2}}{\vartheta^{2}} \frac{\sigma_{\sigma}}{1-\rho_{\sigma}^{2}}}_{\beta_{\sigma, H M L}} \cdot \frac{1-\rho_{\sigma}^{2}}{\sigma_{\sigma}} \cdot\left(\frac{\widetilde{\beta}_{i} \sigma_{i, t}-\widetilde{\beta}_{j} \sigma_{j, t}}{2}\right),
\end{aligned}
$$

where $B, D_{i}$, and $D_{j}$ are defined in Lemma 1 . Notice that both $\beta_{\sigma, F P P}$ and $\beta_{\sigma, H M L}$ are positive for values of $\gamma>1$ (i.e. for values of $\vartheta<0$ ).

The UIP regression amounts to the following version of equation (A14):

$$
\Delta e_{t+1}^{i, j}=\widehat{\alpha}_{F P P}+\widehat{\beta}_{F P P}\left(r_{i, t}-r_{j, t}\right)+\widehat{\xi}_{t+1}
$$

We are interested in characterizing the regression coefficient $\widehat{\beta}_{F P P}$ :

$$
\begin{aligned}
\widehat{\beta}_{F P P} & =\frac{\operatorname{Cov}\left[\Delta e_{t+1}^{i, j},\left(r_{i, t}-r_{j, t}\right)\right]}{\operatorname{Var}\left(r_{i, t}-r_{j, t}\right)} \\
& =\frac{\operatorname{Cov}\left[\alpha_{F P P}+\left(r_{i, t}-r_{j, t}\right)+\beta_{\sigma, F P P}\left(\sigma_{i, t}-\sigma_{j, t}\right)+\beta_{\sigma, H M L}\left(\frac{\widetilde{\beta}_{i} \sigma_{i, t}-\widetilde{\beta}_{j} \sigma_{j, t}}{2}\right),\left(r_{i, t}-r_{j, t}\right)\right]}{\operatorname{Var}\left(r_{i, t}-r_{j, t}\right)} \\
& =\frac{\operatorname{Var}\left(r_{i, t}-r_{j, t}\right)}{\operatorname{Var}\left(r_{i, t}-r_{j, t}\right)}+\frac{\operatorname{Cov}\left[\beta_{\sigma, F P P}\left(\sigma_{i, t}-\sigma_{j, t}\right)+\beta_{\sigma, H M L}\left(\frac{\tilde{\beta}_{i} \sigma_{i, t}-\tilde{\beta}_{j} \sigma_{j, t}}{2}\right),\left(r_{i, t}-r_{j, t}\right)\right]}{\operatorname{Var}\left(r_{i, t}-r_{j, t}\right)} .
\end{aligned}
$$


Using the expression for the interest rate differential in (A9), we get:

$$
\begin{aligned}
\widehat{\beta}_{F P P} & =1+\beta_{\sigma, F P P}\left(\frac{1}{\vartheta}-\frac{1}{2}\right) \frac{\operatorname{Var}\left(\sigma_{i, t}-\sigma_{j, t}\right)}{\operatorname{Var}\left(r_{i, t}-r_{j, t}\right)}+\beta_{\sigma, H M L}\left(\frac{1}{\vartheta}-\frac{1}{2}\right) \cdot \frac{\left(\widetilde{\beta}_{i}+\widetilde{\beta}_{j}\right)}{2} \cdot \frac{\operatorname{Var}\left(\sigma_{i, t}-\sigma_{j, t}\right)}{\operatorname{Var}\left(r_{i, t}-r_{j, t}\right)} \\
& =1+\underbrace{\left(\frac{1}{\vartheta}-\frac{1}{2}\right)}_{<0} \cdot \underbrace{\left(\beta_{\sigma, F P P}+\frac{\left(\widetilde{\beta}_{i}+\widetilde{\beta}_{j}\right)}{2} \cdot \beta_{\sigma, H M L}\right)}_{>0} \cdot \underbrace{\frac{\operatorname{Var}\left(\sigma_{i, t}-\sigma_{j, t}\right)}{\operatorname{Var}\left(r_{i, t}-r_{j, t}\right)}}_{>0},
\end{aligned}
$$

which concludes the proof.

Proof of Corollary 1. For the special case of time additive preferences (i.e. $\gamma \rightarrow 1$ or $\vartheta \rightarrow-\infty)$, note that:

$$
\operatorname{Var}\left(r_{i, t}-r_{j, t}\right)=\operatorname{Var}\left(z_{i, t}-z_{j, t}\right)+\frac{1}{4} \operatorname{Var}\left(\sigma_{i, t}-\sigma_{j, t}\right), \quad \beta_{\sigma, F P P} \rightarrow \frac{1}{2}, \quad \beta_{\sigma, H M L} \rightarrow 0
$$

and conclude that

$$
\widehat{\beta}_{F P P}=1-\underbrace{\frac{\frac{1}{4} \operatorname{Var}\left(\sigma_{i, t}-\sigma_{j, t}\right)}{\operatorname{Var}\left(z_{i, t}-z_{j, t}\right)+\frac{1}{4} \operatorname{Var}\left(\sigma_{i, t}-\sigma_{j, t}\right)}}_{\in(0,1)} .
$$




\section{B Derivations for General Equilibrium Model}

\section{B.1 Allocations as a Function of Pareto weights}

Let $W_{t}^{i}=W\left(C_{t}^{i}, U_{t+1}^{i}\right)$ be the right-hand side of equation (9). If we denote the partial derivatives of the aggregator $W^{i}$ as follows,

$$
W_{1, t}^{i}:=\frac{\partial W_{t}^{i}}{\partial C_{t}^{i}}, \quad W_{2, t}^{i}:=\frac{\partial W_{t}^{i}}{\partial U_{t+1}^{i}},
$$

the stochastic discount factor is equal to

$$
M_{t+1}^{i}=\frac{W_{2, t}^{i} W_{1, t+1}^{i}}{W_{1, t}^{i}} \quad \forall i=\{h, f\} .
$$

The optimality condition for the allocation of good $X_{j, t}$ for $t=1,2, \ldots$ in each possible state is

$$
\mu_{0}^{j} \cdot\left(\prod_{k=0}^{t-1} W_{2, k}^{j}\right) \cdot W_{1, t}^{j} C_{t}^{j} \frac{\alpha}{x_{j, t}^{j}}=\frac{(1-\alpha)}{(N-1)} \cdot \frac{1}{x_{j, t}^{i}} C_{t}^{i} W_{1, t}^{i} \cdot\left(\prod_{k=0}^{t-1} W_{2, k}^{i}\right) \cdot \mu_{0}^{j}
$$

for all countries $i \neq j$. Define the time $t$ Pareto weights as

$$
\begin{aligned}
\mu_{t}^{i} & =\mu_{0}^{i} \cdot\left(\prod_{j=0}^{t-1} W_{2, j}^{i}\right) \cdot W_{1, t}^{i} C_{t}^{i} \\
& =\mu_{t-1}^{i} \cdot W_{2, t-1}^{i} \cdot \frac{W_{1, t}^{i}}{W_{1, t-1}^{i}} \cdot \frac{C_{t}^{i}}{C_{t-1}^{i}}=\mu_{t-1}^{i} \cdot M_{t}^{i} \cdot \exp \left\{\Delta c_{t}^{i}\right\}, \quad \forall i \in\{h, f\}
\end{aligned}
$$

It follows that equation (B16) can be rewritten as

$$
\mu_{t}^{j} \cdot \frac{\alpha}{x_{j, t}^{j}}=\frac{(1-\alpha)}{(N-1)} \cdot \frac{1}{x_{j, t}^{i}} \cdot \mu_{t}^{i}
$$


Let $S_{j, t}:=\mu_{j, t} / \mu_{1, t}$. Then the optimality condition in equation (B17) combined with the feasibility constraint can be represented by the following system of recursive equations:

$$
\begin{aligned}
x_{i, t}^{i} & =\left(1+\frac{1-\alpha}{\alpha(N-1)} \sum_{j \neq i} \frac{S_{j, t}}{S_{i, t}}\right)^{-1} X_{i, t}, \quad \forall i \in\{1,2, \ldots, N\} \\
x_{i, t}^{j} & =\frac{1-\alpha}{\alpha} \frac{1}{N-1} \frac{S_{j, t}}{S_{i, t}} x_{i, t}^{i}, \quad \forall i \neq j \in\{1,2, \ldots, N\} \\
S_{j, t} & =S_{j, t-1} \cdot \frac{M_{j, t}}{M_{1, t}} \cdot\left(\frac{C_{j, t} / C_{j, t-1}}{C_{1, t} / C_{1, t-1}}\right), \quad \forall t \geq 1 .
\end{aligned}
$$

We use perturbation methods to solve our system of equations (8)-(17). We compute our policy functions using the dynare++4.2.1 package. All variables are expressed in log-units.

\section{B.2 Terms of Trade, Imports, and Exports}

We normalize the price of good 1 to 1 . The terms of trade can be obtained from the intratemporal condition:

$$
-p_{j, t} \frac{C_{t}^{1}}{x_{1, t}^{1}} \alpha+\frac{1-\alpha}{N-1} \frac{C_{t}^{1}}{x_{j, t}^{1}}=0, \quad \forall j=\{2,3, \ldots, N\}
$$

which implies

$$
p_{j, t}=\frac{1-\alpha}{\alpha(N-1)} \frac{x_{1, t}^{1}}{x_{j, t}^{1}}, \quad \forall j=\{2,3, \ldots, N\} .
$$

Consider country 1 and country $j$. The exports of country 1 to country $j$ are

$$
\operatorname{Exp}_{1, t}^{j}=x_{1, t}^{j},
$$


where $x_{1, t}^{j}$ is defined in equation (14). The imports of country 1 from country $j$ are

$$
\begin{aligned}
\operatorname{Imp}_{j, t}^{1} & =p_{j, t} \cdot x_{j, t}^{1}=\frac{1-\alpha}{\alpha} \frac{1}{N-1} \frac{x_{1, t}^{1}}{x_{j, t}^{1}} x_{j, t}^{1} \\
& =\frac{1-\alpha}{\alpha} \frac{1}{N-1}\left(1+\frac{1-\alpha}{\alpha(N-1)} \sum_{j \neq 1} S_{j, t}\right)^{-1} X_{1, t} .
\end{aligned}
$$

It follows that the volume of trade between countries 1 and $j$ normalized by the endowment of country 1 is

$$
\begin{aligned}
\frac{V o l_{1, t}^{j}}{X_{1, t}} & =\frac{\frac{1-\alpha}{\alpha} \frac{1}{N-1}\left(1+S_{t}^{j}\right)}{1+\frac{1-\alpha}{\alpha} \frac{1}{N-1} \sum_{j \neq 1} S_{t}^{j}} \\
& =\frac{(1-\alpha) \cdot\left(1+S_{t}^{j}\right)}{\alpha(N-1)+(1-\alpha) \sum_{j \neq 1} S_{t}^{j}} .
\end{aligned}
$$

Similarly, the net exports-output ratio between countries 1 and $j$ is

$$
\begin{aligned}
\frac{N X_{1, t}^{j}}{X_{1, t}} & =\frac{\frac{1-\alpha}{\alpha} \frac{1}{N-1}\left(S_{t}^{j}-1\right)}{1+\frac{1-\alpha}{\alpha} \frac{1}{N-1} \sum_{j \neq 1} S_{t}^{j}} \\
& =\frac{(1-\alpha) \cdot\left(S_{t}^{j}-1\right)}{\alpha(N-1)+(1-\alpha) \sum_{j \neq 1} S_{t}^{j}} .
\end{aligned}
$$

\section{CHomogeneous Exposure: Inspecting the Mechanism}

In this section, we explore further the basic properties of a recursive risk-sharing scheme with multiple countries with homogeneous exposure to endowment shocks. We show that in terms of allocation dynamics, a multicountry economy preserves the basic success of a two-country setting. In terms of risk-sharing measurements, in contrast, we highlight several relevant differences. 
Response to shocks. In Figure C1 we report the response of some variables of interest to short- and long-run local shocks. For the sake of the exposition we consider the case in which country 1 receives a positive local shock. That is, country 1 receives a positive shock (panels labeled $\Delta x$ ), whereas the remaining countries experience no change in their endowment. Since all countries share the same calibration, both the endowments and the pseudo-Pareto weight dynamics of countries 2-5 are identical. Because of our symmetric calibration, in this section we denote country 1 as the home country and refer to the remaining countries as the foreign countries.

The risk-sharing arrangement in this economy prescribes that in response to both a positive short- and long-run shock to the home country, the foreign countries experience an equal increase of their share of world consumption (panels labeled $s$ ). Specifically, upon the arrival of a positive endowment shock, the marginal utility of country 1 declines substantially because of home bias. In order to re-establish the equality of marginal utilities across countries, goods are reallocated toward the foreign countries. In both cases the real exchange rate of country 1 depreciates because of the larger current (expected) supply of the domestic good associated with a positive short-run (long-run) shock (panels labeled $\Delta e$ ).

The panels of Figure C1 labeled $\Delta c$ document a different response of consumption growth rates with respect to short- and long-run shocks. When a positive short-run shock materializes, consumption increases in the entire cross section of countries, as only part of country 1's additional resources are being redistributed abroad. In response to positive long-run news, in contrast, consumption drops in the home country as the risk-sharing redistribution effect dominates. The foreign countries experience a positive growth rate of consumption which is required to equalize their marginal utilities to that of the home country.

This differential response of consumption to short- and long-run endowment shocks 

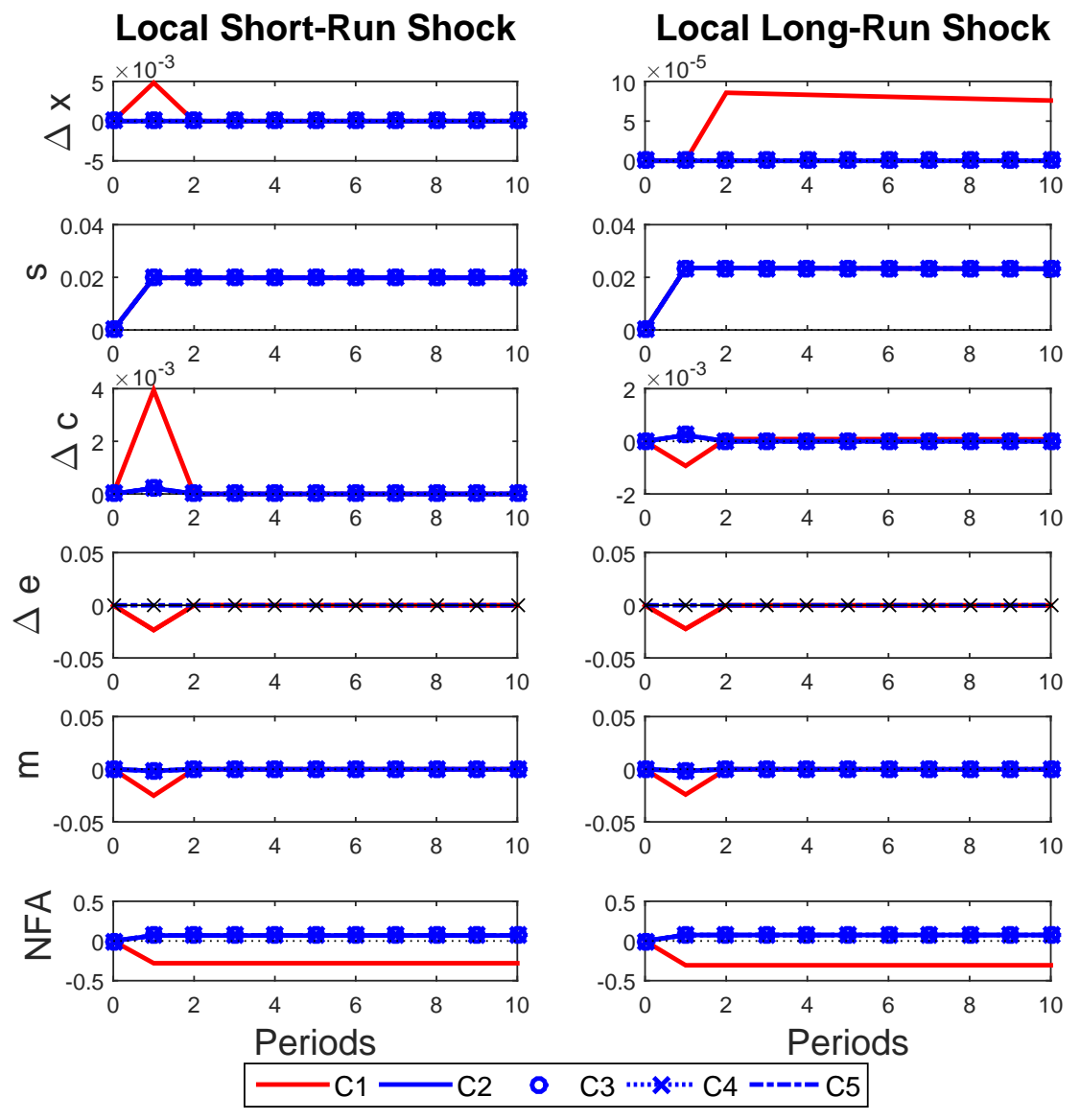

Fig. C1 - Impulse response functions under homogeneous exposure. The left (right) panels report the response of endowment growth $\left(\Delta \log X^{i}\right)$, relative Pareto weights (log $\left.S_{j} / S_{1}\right)$, consumption growth $\left(\Delta c_{i}\right)$, exchange rate growth $\left(\Delta e_{3}^{i}\right)$, stochastic discount factors $\left(m_{i}\right)$, and net foreign assets $\left(A_{i} / X_{i}\right)$ to a one-standard-deviation short-run (long-run) shock to the endowment of country 1 only. All panels refer to the case in which the economy consists of 5 countries $(i=1, \ldots, 5)$. The exchange rate is measured with respect to country 3 , implying that $\Delta e<0$ for country 1 denotes a depreciation of its real exchange rate with respect to country 3 .

results in the spread between country 1's and other the countries' consumption being positive in one case and negative in the other. Since country 1's exchange rate depreciates in response to both types of shocks, the model produces a less-than-perfect correlation between currency movements and consumption differentials, as in the data (Backus and Smith 1993) and as already shown by Colacito and Croce (2013).

The last two panels in Figure $\mathrm{C} 1$ report the response of the net foreign assets (henceforth NFA) to the two types of shock. The country that receives either a positive 
short- or long-run shock acts as insurance provider to the other countries. As a consequence, it experiences a drop in its NFA. This negative link between NFA and positive exogenous shocks induced by our risk-sharing motive plays a crucial role in the next sections, i.e., once we account for heterogeneity.

Simulated moments. In Table C1 we report the results of our analysis. Specifically, we analyze how several moments of interest change as the number of countries in the economy $(N C)$ increases from 2 to 5 . We obtain several relevant results as the number of countries increases.

First, country-level consumption volatility decreases. This is a direct reflection of the better risk-sharing opportunities that are available in a multicountry economy. A similar argument can be used to explain the decline in the volatility of both the pseudo-Pareto weights and the net-exports-to-output ratio. Second, the bilateral correlations of both consumption growth rates and stochastic discount factors decline. Under complete markets, less-correlated discount factors immediately imply more volatile bilateral exchange rates. At a country level, hence, better risk-sharing opportunities are not necessarily accompanied by higher correlations of consumption profiles and smoother exchange rates (Brandt et al. 2006).

Third, international correlations and exchange rate volatility are very sensitive to the trade dynamics arising from our recursive risk sharing. We construct trade-weighted variables by weighting each country's stochastic discount factor and exchange rate in proportion to its volume of trade with country 1 (see equation (18)). As documented in the panel labeled "Trade-Weighted Moments," when the number of countries rises the trade-weighted correlation of stochastic discount factors increases, in contrast to what is obtained for bilateral correlations. The intuition for this result is that correlations tend to be larger between countries that are major trading partners. By no-arbitrage, 
TABLE C1: Simulated Moments with Homogeneous Exposure

\begin{tabular}{lcccc}
\hline \hline & $N C=2$ & $N C=3$ & $N C=4$ & $N C=5$ \\
\hline $\operatorname{Std}(\Delta y)$ & 1.94 & 1.94 & 1.94 & 1.93 \\
$\operatorname{ACF}_{1}(\Delta y)$ & 0.07 & 0.07 & 0.07 & 0.06 \\
$\operatorname{corr}\left(\Delta y_{t}^{h}, \Delta y_{t}^{f}\right)$ & 0.25 & 0.25 & 0.25 & 0.24 \\
\hline Single-Country Moments & & & & \\
\hline $\operatorname{Std}(\Delta c)$ & 1.78 & 1.75 & 1.74 & 1.72 \\
$\operatorname{ACF}_{1}(\Delta c)$ & 0.07 & 0.07 & 0.07 & 0.06 \\
\hline Bilateral Moments & & & & \\
\hline $\operatorname{corr}\left(\Delta c_{t}^{h}, \Delta c_{t}^{f}\right)$ & 0.49 & 0.43 & 0.4 & 0.38 \\
$\operatorname{Std} \Delta e$ & 14 & 15.14 & 15.47 & 15.72 \\
$\operatorname{corr}\left(m, m^{f}\right)$ & 0.94 & 0.93 & 0.93 & 0.93 \\
$\operatorname{corr}\left(\Delta c^{h}-\Delta c^{f}, \Delta e\right)$ & 0.31 & 0.42 & 0.45 & 0.47 \\
$\operatorname{Std}[N X / X]$ & 2.04 & 1.80 & 1.80 & 1.80 \\
$\operatorname{Std}\left[\mu / \sum \mu\right]$ & 21.25 & 17.42 & 14.65 & 12.34 \\
\hline $\operatorname{Trade}-$ Weighted Moments & & & & \\
Std $\Delta e^{w}$ & 14 & 13.80 & 13.52 & 13.37 \\
$\operatorname{corr}\left(m, m^{w}\right)$ & 0.94 & 0.95 & 0.95 & 0.95 \\
\hline Financial Variables & & & & \\
\hline $\operatorname{E}\left[r_{f}\right]$ & 2.29 & 2.36 & 2.32 & 2.34 \\
$\operatorname{Std}\left[r_{f}\right]$ & 0.31 & 0.32 & 0.31 & 0.30 \\
$\operatorname{corr}\left(r_{f}^{h}, r_{f}^{f}\right)$ & 0.93 & 0.93 & 0.92 & 0.92 \\
$\operatorname{Std}[M] / \mathrm{E}[M]$ & 40.46 & 41.35 & 42.01 \\
$\operatorname{Std}[N F A / X] /$ Std $(\Delta y)$ & 10.41 & 12.15 & 12.09 & 12.47 \\
$\beta_{U I P}[H M L]$ & -4.08 & -5.75 & -5.27 & -5.35 \\
E $[H M 1$ & -0.25 & -0.19 & -0.02 \\
\hline
\end{tabular}

Notes - The table reports annualized simulated moments from the model with homogeneous exposure as the number of countries in the economy $(N C)$ ranges from 2 to 5 . All parameters are set to their benchmark values reported in Table 2. The first panel reports the moments for the dynamics of exogenous endowments' growth rates. The panel labeled "Single-Country Moments" reports the moments of the consumption growth rate within each country. The panel labeled "Bilateral Moments" reports the cross-country moments for each country pair. The panel labeled "Trade-Weighted Moments" reports the moments for the case in which each foreign country is weighted in proportion to its volume of trade with country 1 . The panel labeled "Financial Variables" reports the moments for the risk-free rates $\left(r_{f}\right)$, stochastic discount factors $(M)$, net foreign assets to output ( $N F A$ ), excess returns $(r x)$, slope coefficient of the UIP regressions $\left(\beta_{U I P}\right)$, and average currency risk premium (E[HML]).

a higher correlation between the home country and the trade-weighted rest of the world results in a smoother exchange rate. 
CRRA case. In Table $\mathrm{C} 2$ we report some moments of interest for the special case of constant relative risk aversion preferences (henceforth CRRA). This case is obtained by imposing that the IES $(\psi)$ equals the inverse of the RRA coefficient $(\gamma)$. Specifically, we set $\psi=1 / 6.5$, and keep all other values to their benchmark values.

This experiment highlights three relevant results. First, in a world with multiple goods and time-additive preferences, the volatility of the bilateral real exchange rate is still a misleading indicator of risk sharing, as in the case of recursive preferences.

Second, since growth news shocks are not priced, the risk-sharing motives are solely driven by short-run risk. As a result, the long-run risk-sharing opportunities that arise with an increasing number of countries play no role in the determination of $S^{j}$, and the consumption growth rates are predominantly driven by the properties of the exogenous short-run shocks. Since short-run shocks are poorly correlated internationally, as $N C$ increases, the consumption bundle of each country features a larger number of goods with low correlations. By construction, a trade-weighted measure of the cross-country correlation of the discount factors reproduces the same pattern of the bilateral correlation, in contrast to what is seen with recursive preferences.

Summarizing, in an economy in which growth news shocks are not priced, the risksharing measures proposed by Brandt et al. (2006) may be misleading, regardless of whether they are bilateral or trade weighted. In an economy in which news shocks are priced, in contrast, cross-country correlations are directly related to trade volume, and hence trade-weighted measures of risk sharing may be more accurate.

Last but not least, we note that, absent trading motives associated with long-run news, well-known anomalies continue to be present even in our multicountry setting. 
TABLE C2: Simulated Moments (CRRA case)

\begin{tabular}{lcccc}
\hline \hline & $N C=2$ & $N C=3$ & $N C=4$ & $N C=5$ \\
\hline Risk-sharing measures & & & & \\
\hline Std $\Delta e$ & 10.21 & 11.15 & 11.5 & 11.7 \\
$\operatorname{corr}\left(m, m^{f}\right)$ & 0.59 & 0.49 & 0.45 & 0.42 \\
$\operatorname{corr}\left(m, m^{w}\right)$ & 0.59 & 0.56 & 0.56 & 0.55 \\
\hline & & & & \\
Anomalies & 1 & 1 & 1 & 1 \\
\hline $\operatorname{corr}\left(\Delta c^{h}-\Delta c^{f}, \Delta e\right)$ & 1.00 & 0.94 & 0.99 & 0.99 \\
$\beta_{U I P}$ & n.a. & 0.00 & 0.00 & 0.00 \\
E $[H M L]$ &
\end{tabular}

Notes - The table reports simulated annualized moments as the number of countries in the economy (NC) ranges from 2 to 5 . All parameters are set to their benchmark values reported in Table 2 except for $\psi=1 / 6.5$ (the CRRA case). The average correlation of the stochastic discount factors across country pairs is denoted as $\operatorname{corr}\left(m, m^{f}\right)$. The correlation of the country 1 stochastic discount factor with the volume of the trade-weighted stochastic discount factors of the remaining countries is denoted by $\operatorname{corr}\left(m, m^{w}\right)$.

\section{Additional Empirical Results}

In Figure D2, we report the quintiles of the cross-sectional distribution to which the US and the Japanese real interest rate belonged to from 1975 to 2013. Specifically, for each G-10 country we compute its average real interest rate using overlapping 5-year rolling windows. This procedure allows us to create a balanced panel of annual real rates for our G-10 countries. In each year, we compute the cross-section of our 10 real rates and identify the quintile corresponding to the US and the Japanese real interest rate, respectively. A value of 1 (5) means that the interest rate is in the bottom (top) $20 \%$ of the cross-sectional distribution.

The US real rate was on the high side of the cross-sectional distribution in the first part of the post-Bretton-Woods era, but has moved toward the low side over time (panel (a) of Figure D2). An econometrician focusing on the entire sample would conclude that the US has, on average, a median interest rate, whereas someone looking at our post-1987 sample would conclude that the US is a below-median country. For 


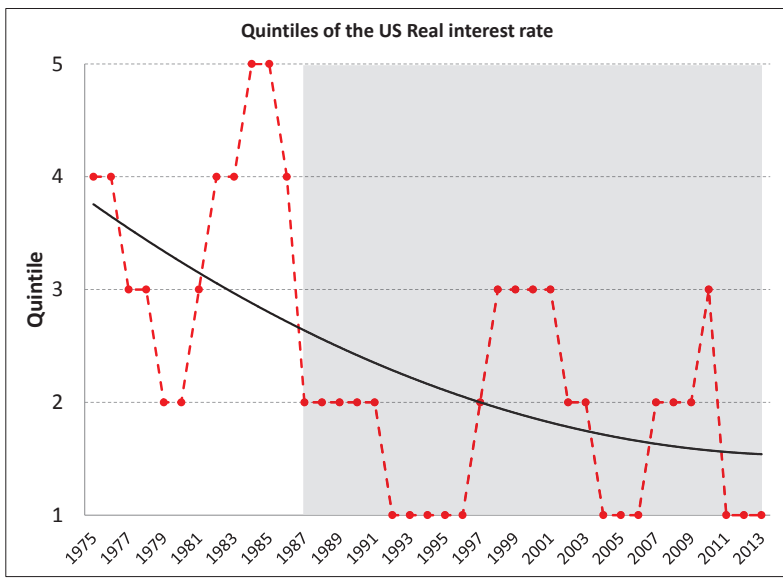

(a)

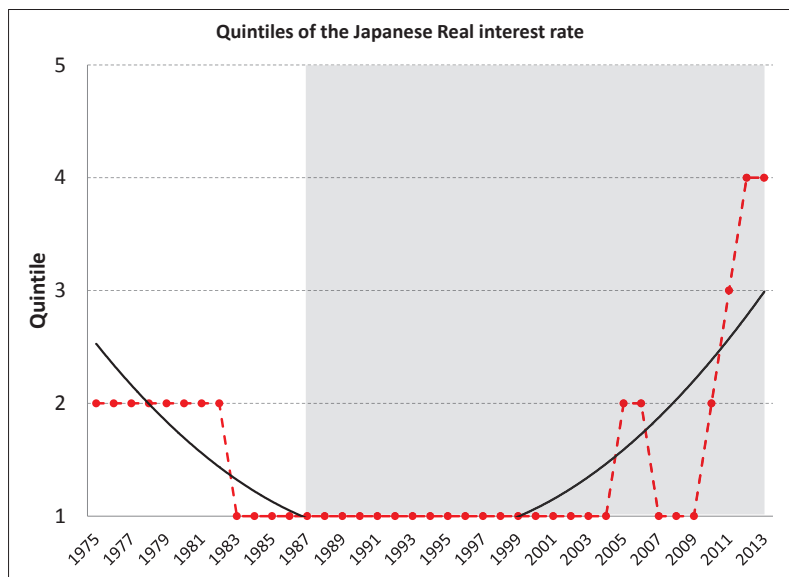

(b)

FIG. D2 - Panel (a) (Panel (b)) reports the quintiles to which the US (Japanese) real interest rate belongs during the period 1975-2013 (dashed-dot line). In each panel, (i) the solid line represents a quadratic fit of the time series of quintiles, and (ii) a value of 1 (5) means that the interest rate is in the bottom (top) $20 \%$ of the cross-sectional distribution for G-10 countries. The grey area denotes the sample that we consider in our empirical analysis.

Japan, the real interest rate was firmly in the bottom part of the cross-sectional distribution until the early 2000's, but sharply increased in the most recent part of the sample. In our post-1987 sample, the Japanese interest rate has on average been low, but has not always been among the lowest quintile in the cross-section of our G-10 countries.

We explore the relation between the cross section of $\beta$ 's and international capital flows during the 2007-2008 Great Recession. This period is characterized by severe negative global news shocks that affected all countries in our cross-section. The year 2008, in particular, represents the lowest realization of our global long-run risk variable. Our model would predict that upon the occurrence of a negative shock, negative $\beta$ countries (i.e., the countries that are less exposed to global shocks) should provide insurance to the countries with large positive $\beta$ 's (i.e., the countries with a large degree of exposure to global shocks). That is, countries with lower exposure should experience a deterioration of their net foreign asset positions. Our results provide empirical 


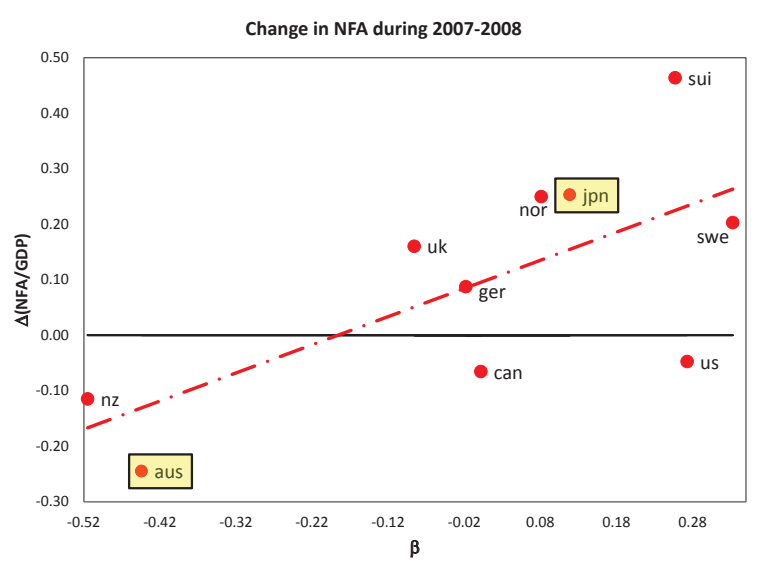

(a)

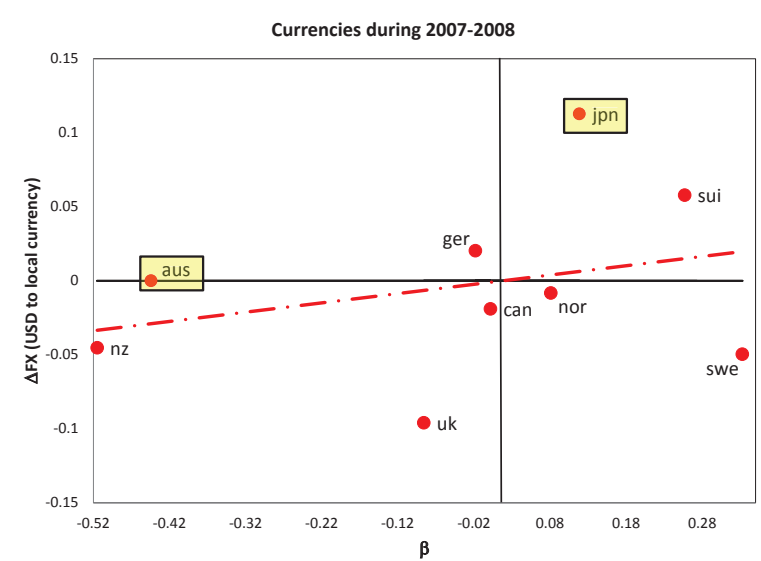

(b)

FIG. D3 - Panel (a) reports the change in the average net foreign asset position of each country during 2008-2009 over the average of the previous two years against the $\beta$ of the corresponding country. The estimated $\beta$ 's are reported in Table 1 . Panel (b) reports the average change in exchange rate of each country vis $a$ vis the US Dollar during 2008-2009 against the $\beta$ of the corresponding country. The estimated $\beta$ 's are reported in Table 1 . All changes are in excess of the appreciation rate of the Australian dollar (-1.5\% in our sample). The reported value for AUS is therefore equal to zero by construction.

support for this prediction by showing that in 2008-2009, Australia and New Zealand experienced a large drop in their net foreign asset positions, while countries on the other end of the spectrum, such as Japan, Sweden, and Switzerland, experienced a large accumulation of foreign assets (see panel (a) in Figure D3).

Furthermore, the currencies of countries with large positive $\beta$ 's appreciated relative to those of countries with negative $\beta$ 's during the Great Recession (see panel (b) in Figure D3). Take, for example, Japan (a positive $\beta$ country) and Australia (a negative $\beta$ country): during 2008-2009, the Japanese yen appreciated by an average of about $10 \%$ per year relative to the Australian dollar. This is exactly what our model predicts, as shown in Figure 2.

Table D3 concludes this section by reporting the $\beta$ 's of the portfolios used to carry out 
TABLE D3: Portfolio $\beta$ 's of Conditional Analysis

\begin{tabular}{|c|c|c|c|c|c|c|c|c|c|c|}
\hline \multirow[b]{2}{*}{ Portfolio } & \multicolumn{4}{|c|}{ Exchange Rate } & \multicolumn{6}{|c|}{ Net Foreign Assets } \\
\hline & {$[1]$} & {$[2]$} & {$[3]$} & [4] & [5] & [6] & [7] & {$[8]$} & [9] & [10] \\
\hline & -0.48 & -0.48 & -0.48 & & -0.48 & -0.48 & & -0.48 & -0.48 & -0.48 \\
\hline & 0.02 & -0.01 & 0.02 & $-0 .($ & 0.02 & 0.02 & -0.01 & 0.02 & 0.02 & -0.01 \\
\hline & 0.30 & 0.30 & 0.30 & 0.30 & 0.29 & 0.30 & 0.29 & 0.29 & 0.30 & 0.29 \\
\hline
\end{tabular}

Notes - The table reports the $\beta$ 's of the portfolios associated to the analysis in Table 4 of main text.

the analysis in Table 4 of main text. 